\title{
Demonstrating the application of the urban exposome framework using drinking water and quality of life indicators: a proof-of-concept study in Limassol, Cyprus
}

Xanthi D Andrianou ${ }^{1}$, Chava van der Lek ${ }^{1,2}$, Pantelis Charisiadis ${ }^{3}$, Solomon Ioannou ${ }^{3}$, Kalliopi N Fotopoulou ${ }^{1}$, Zoe Papapanagiotou ${ }^{4}$, George Botsaris ${ }^{4}$, Carijn Beumer ${ }^{2}$, Konstantinos C Makris ${ }^{\text {Corresp. } 3}$

${ }^{1}$ Cyprus International Institute for Environmental and Public Health, Cyprus University of Technology, Limassol, none, Cyprus

2 Department of Health, Ethics and Society, Faculty of Health, Maastricht University, Maastricht, Netherlands

3 Cyprus International Institute for Environmental and Public Health, Cyprus University of Technology, LImassol, none, Cyprus

Department of Agricultural Sciences, Biotechnology and Food Sciences, Cyprus University of Technology, Limassol, Cyprus

Corresponding Author: Konstantinos C Makris

Email address: konstantinos.makris@cut.ac.cy

Background. Cities face rapid changes leading to increasing inequalities and emerging public health issues that require cost-effective interventions. The urban exposome concept refers to the continuous monitoring of urban environmental and health indicators using the city and smaller inter-city areas as measurement units in an interdisciplinary approach that combines qualitative and quantitative methods from social sciences, to epidemiology and exposure assessment.

Methods. In this proof of concept study, drinking water and quality of life indicators were described as part of the development of the urban exposome of Limassol (Cyprus) and were combined with agnostic environment-wide association analysis (EWAS). This study was conducted as a two-part project with a qualitative part assessing the perceptions of city stakeholders, and quantitative part using a crosssectional study design (an urban population study). We mapped the water quality parameters and participants' opinions on city life (i.e. neighborhood life, health care and green space access) using quarters (small administrative areas) as the reference unit of the city. In an exploratory, agnostic, environment-wide association study analysis, we used all variables (questionnaire responses and water quality metrics) to describe correlations between.

Results. Overall, urban drinking-water quality using conventional indicators of chemical (disinfection byproducts-trihalomethanes) and microbial (coliforms, E. coli, and Enterococci) quality did not raise particular concerns. The general health and chronic health status of the urban participants were significantly (FDR corrected p-value<0.1) associated with different health conditions such as hypertension and asthma, as well as having financial issues in access to dental care. Additionally, correlations between trihalomethanes exposures and participant behavioral characteristics (e.g. household cleaning, drinking water habits) were documented.

Conclusion. This proof-of-concept study showed the potential of using integrative approaches to develop urban exposomic profiles and identifying within-city differences in environmental and health indicators. The characterization of the urban exposome of Limassol will be expanded via the inclusion of biomonitoring tools and untargeted metabolomics. 


\section{Demonstrating the application of the urban exposome} 2 framework using drinking water and quality of life 3 indicators: a proof-of-concept study in Limassol, Cyprus

5 Xanthi D. Andrianou ${ }^{1}$, Chava van der Lek ${ }^{1,2}$, Pantelis Charisiadis ${ }^{1}$, Solomon Ioannou ${ }^{1}$, Kalliopi

6 N. Fotopoulou ${ }^{1}$,Zoe Papapanagiotou ${ }^{3}$, George Botsaris ${ }^{3}$, Carijn Beumer ${ }^{2}$, Konstantinos C. Makris $^{1}$ 7

$8{ }^{1}$ Cyprus International Institute for Environmental and Public Health, Cyprus University of 9 Technology, Limassol, Cyprus

$10{ }^{2}$ Department of Health, Ethics and Society, Faculty of Health, Medicine and Life Sciences, 11 Maastricht University, Maastricht, the Netherlands

$12{ }^{3}$ Department of Agricultural Sciences, Biotechnology and Food Sciences, Cyprus University of 13 Technology, Limassol, Cyprus

14

15 Corresponding Author:

16 Konstantinos C. Makris ${ }^{1}$

17 Irinis 95, Limassol, Cyprus

18 Email address: konstantinos.makris@cut.ac.cy 
19 Abstract

20 Background. Cities face rapid changes leading to increasing inequalities and emerging public

21 health issues that require cost-effective interventions. The urban exposome concept refers to the 22 continuous monitoring of urban environmental and health indicators using the city and smaller 23 inter-city areas as measurement units in an interdisciplinary approach that combines qualitative 24 and quantitative methods from social sciences, to epidemiology and exposure assessment. Methods. In this proof of concept study, drinking water and quality of life indicators were described as part of the development of the urban exposome of Limassol (Cyprus) and were combined with agnostic environment-wide association analysis (EWAS). This study was conducted as a two-part project with a qualitative part assessing the perceptions of city stakeholders, and quantitative part using a cross-sectional study design (an urban population study). We mapped the water quality parameters and participants' opinions on city life (i.e. neighborhood life, health care and green space access) using quarters (small administrative areas) as the reference unit of the city. In an exploratory, agnostic, environment-wide association study analysis, we used all variables (questionnaire responses and water quality metrics) to describe correlations between. Results. Overall, urban drinking-water quality using conventional indicators of chemical (disinfection byproducts-trihalomethanes) and microbial (coliforms, E. coli, and Enterococci) quality did not raise particular concerns. The general health and chronic health status of the urban participants were significantly (FDR corrected $p$-value $<0.1$ ) associated with different health conditions such as hypertension and asthma, as well as having financial issues in access to dental care. Additionally, correlations between trihalomethanes exposures and participant behavioral characteristics (e.g. household cleaning, drinking water habits) were documented.

42 Conclusion. This proof-of-concept study showed the potential of using integrative approaches to 43 develop urban exposomic profiles and identifying within-city differences in environmental and 44 health indicators. The characterization of the urban exposome of Limassol will be expanded via the inclusion of biomonitoring tools and untargeted metabolomics. 


\section{Introduction}

48 The definition of the exposome in 2005 by Dr. Wild introduced a paradigm in environmental and 49 population health research, which promotes studies that either encompass simultaneous assessment of multiple exposures of the general population or focus on specific time windows of susceptibility (i.e. pregnancy), to capture the totality of environmental/lifestyle/behavioral exposures (Wild, 2005; Robinson et al., 2015; Andra et al., 2015; Cui et al., 2016). The definition of the exposome along with the advances in methodologies for high throughput analysis in shorter time has also redefined the study paradigm in environmental health (Buck Louis, Smarr \& Patel, 2017). Thus, decoding the exposome will not benefit only environmental health, but it will lead to better understanding of disease development and progression and it will allow for comprehensive monitoring of environment-disease associations.

The exposome as a paradigm has fostered innovation in exposure assessment. It allows for intraand inter-disciplinary approaches in public health to become more widespread than they are now, as it is indicated by the number of "exposomes" that have been defined to address different totalities and with different units of reference (National Research Council, 2012; Escher et al., 62 2016; Dai et al., 2017).

Cities are dynamic and complex systems that become the future focus of public health systems, because they currently host more than half of the global population and generate $>80 \%$ of the global GDP ("Urban Development Overview"; Zhang, 2011). Using terminology similar to the one used for the human exposome, the urban exposome extends the utility of the human exposome, and it is defined as the totality of indicators (quantitative or qualitative) that shape the quality of life and health of urban populations (Andrianou \& Makris, 2018). Monitoring of these indicators that can be either external or internal city parameters, is not merely the sum of individual human exposures, but places cities and their smaller areas in the center of an urban-oriented study framework, previously defined as the urban exposome framework (Andrianou \& Makris, 2018).

72 Following the urban exposome approach, the quality of life in urban centers is concurrently assessed together with other indicators, such as water quality, or prevalence/incidence of communicable and non-communicable diseases using interdisciplinary methodology. This framework expands previous study approaches where the urban exposome is defined as the sum of exposures in cities (Probst-Hensch, 2017; Robinson et al., 2018), and proposes a more interdisciplinary and holistic approach to assess health determinants of the general population. 
78 To present the first application of the urban exposome framework, we used drinking-water quality 79 metrics and quality of life indicators. As more people nowadays live in cities, providing easy access to safe and affordable water, as well as eliminating possible within-city health and societal disparities becomes more challenging. Besides the technical provisions to maintain water of good quality, the uninterrupted availability of water becomes an issue due to climate change manifestations, especially in areas that are already or expected to be hit harder by extended droughts and other related meteorological phenomena. Europe, overall, is expected to face increases both in the extent of geographical areas affected by droughts and in the duration of such climatic events (Samaniego et al., 2018). Especially, cities located in Southeast Europe and the Mediterranean region are predicted to face challenges in maintaining water availability and adequate water quality in the future (Samaniego et al., 2018). Therefore, cities and their smaller areas (i.e. neighborhoods, or other small administrative areas) are warranted to address waterrelated issues, such as water demand, safety, security and quality issues, while tackling societal inequalities and health disparities. In this context, the concept and the study framework of the urban exposome can be introduced to help scientists and policy makers in the systematic spatiotemporal surveillance and monitoring of a city's heterogeneous health profile.

94 The urban exposome study framework has a hypothesis-generating scope and goes beyond the classical one exposure-one outcome urban studies. Therefore, our aim was to present a proof-ofconcept study using the urban exposome framework to monitor urban health dynamics. The study setting was at Limassol, Cyprus. The urban center of Limassol ("city of Limassol") is defined as a medium-sized city ( 200000 inhabitants according to the 2011 Population Census of Cyprus) ("Population Census 2011," 2014; "Statistics on European cities - Statistics Explained") and it consists of the municipality of Limassol and neighboring municipalities. The city of Limassol currently faces rapid economic development with half of the urban population of the city residing within the municipality of Limassol ( 110000 inhabitants).

103 The specific objective of this analysis was to describe chemical and microbiological parameters of 104 drinking water quality, coupled with quality of life indicators as measured in the Municipality of Limassol, in summer 2017. In this approach we used quarters which are the smallest within-

106 municipality administrative areas, as the unit of reference. To complete the urban exposome of

107 Limassol to the extent possible, additional analysis of routine surveillance data is necessary but it 108 goes beyond the scope of the present analysis. 
109 Materials \& Methods

\section{Application of the urban exposome in the municipality of Limassol, Cyprus}

111 We have previously described the urban exposome as all indicators that need to be continuously 112 monitored for the assessment of city health (Andrianou \& Makris, 2018). Within the framework

113 of the urban exposome, external to the city parameters that cannot be influenced by the city itself

114 can be either general (e.g. global trends and policy decisions) or more specific (e.g. climate change

115 impacts, demographic changes, culture). It follows that internal parameters are those that are

116 integral to the city, such as infrastructure, built/neighborhood environment and determinants of

117 population health (e.g. socioeconomic factors). Either external or internal to the city parameters

118 described before can influence and be influenced by each other both horizontally (within each

119 domain) and/or vertically (between domains). A study was conducted in the summer of 2017 to

120 describe the water and quality of life aspects of the urban exposome of Limassol, following an

121 integrative and interdisciplinary approach (Figure 1). This approach included the following parts:

122 - A perceptions survey with a mixed-methods approach to evaluate the perceptions of

123 stakeholders (i.e. citizens and municipality officials) about the quality of life and certain

124 environmental risks (e.g. chemical and microbial risks in drinking-water) in the city.

- A cross-sectional urban population study with a short questionnaire and collection of tap water samples from households distributed in the quarters of the municipality of Limassol to evaluate water quality indicators and citizens' attitudes about the environment, quality of life in the city and self-reported health status.

129 In this analysis, we focus on the general external urban exposome through the perceptions study 130 and the internal urban exposome through the inclusion of drinking water chemical/microbiological 131 indicators, responses on neighborhood's quality of life and participant characteristics (Figure 1).

132 Using the human exposome framework as a reference, this study also explored the human 133 exposome domains, i.e., the general external domain (perceptions study), the specific external 134 domain (drinking water and quality of life indicators) and the internal domain (participant 135 characteristics) (Figure 1). 


\section{Perceptions study}

137 For the perceptions study, the urban community-based participatory research methodology was 138 applied to actively engage the municipality of Limassol officers and citizens (identified as 139 community stakeholders) about urban health issues (Rojas \& Neutra, 2008). The stakeholders' 140 perceptions were assessed using a mixed methods approach. Face-to-face interviews were 141 conducted, and short questionnaires were administered to the municipality officials (i.e. technical 142 officers from the municipality of Limassol and neighboring municipalities). The questions asked 143 during the face-to-face interviews and the questionnaire for the municipality officers focused on 144 the identification of trends shaping the city of Limassol, assessment of the climate change 145 manifestations and their impact, scoring of environmental health concerns, an assessment of what 146 was believed to be the citizens' major health threats with regards to urban life, and perspectives 147 about future opportunities to improve health in the city. For the citizens' perceptions, an online 148 anonymous questionnaire initially distributed via email among staff at the Cyprus University of 149 Technology campus that is in the municipality of Limassol, and then to the general public via 150 mailing lists maintained at the Cyprus International Institute for Environmental and Public Health 151 for the dissemination of newsletters, and social media (Facebook). This online questionnaire 152 included various questions on climate change perceptions, environmental concerns in general, 153 health perceptions and perceptions about drinking-water quality.

\section{Urban population study}

155 A cross-sectional population study was set up in the municipality of Limassol, Cyprus. Participants $156(\mathrm{n}=132)$ were recruited after being informed about the study through phone calls made in 157 collaboration with the Municipality of Limassol, in the summer of 2017 from all quarters of the 158 municipality, following the 2011 Census population distribution (Table S1). For this study, we 159 also collected urine samples which will be used in the biomonitoring part (measurement of 160 chemical exposures in urine) of the assessment of the urban exposome (not included in this 161 analysis). Thus, sample size estimations were based on the assumption that a total of 120 162 participants randomly selected from the whole municipality would allow us to evaluate the

163 baseline levels of environmental exposures, as according to previous biomonitoring studies a 164 sample of at least 120 randomly selected participants is adequate to capture the $95^{\text {th }}$ percentile of 165 the population levels (Becker et al., 2013). Quarters that are small in area and population, with one 
166 participant, were merged with neighboring ones and three quarters located along the beachfront, 167 each having one participant were also merged together (Figure S1). To ensure high spatial 168 coverage only one participant was recruited per street.

169 Tap water samples were collected from all participating households and in situ measurements of

170 free chlorine were taken during house visits. The drinking water indicators that were assessed were 171 trihalomethanes (THM) along with the free chlorine, from the category of the chemical parameters,

172 and total coliforms, E. coli, Enterococcus spp., Pseudomonas aeruginosa, and total viable counts

173 (TVC) at $22^{\circ} \mathrm{C}$ and $37^{\circ} \mathrm{C}$, from the category of the microbial parameters. These indicators (besides

174 free chlorine) are also routinely monitored in the European Union (EU Council, 1998) . All

175 participants were asked to complete a questionnaire that included, among others, questions about

176 life in their neighborhoods, self-reported health status and drinking water habits. The questionnaire

177 was adapted by the validated urban health and the European Health Survey questionnaires

178 ("Statistical Service - Population and Social Conditions - Health - Announcements - Survey

179 Results: European Health Interview Survey, 2014”; “EURO-URHIS2”; Pope et al., 2016). From

180 this questionnaire the quality of life indicators (e.g. access to health care services, life in the

181 neighborhood and use of green spaces) were assessed.

182 The study was approved by the National Bioethics Committee of Cyprus (decision number:

183 2017/23). All participants read and signed the informed consent documents before data collection.

184 The STROBE statement is available in the supplementary material (Elm et al., 2007).

\section{Water sampling and analysis}

186 The main faucet used for satisfying the water needs of the participating household was selected 187 for drinking-water sampling. The tap water faucet was externally cleaned with ethanol prior to 188 sample collection, and the water was then left to flow freely for $\sim 30$ seconds. Tap water samples 189 for trihalomethanes (THM) analysis were collected in falcon containers with oxidation 190 preservative mixture, while the tap water samples used in the microbial analysis were collected in 191 sterile polypropylene vials. The THM analysis was conducted according to the previously 192 published methods by Charisiadis et al. (Charisiadis et al., 2015). All four THM species were 193 measured in the collected tap water samples from the participating households: chloroform (TCM), 194 bromodichloromethane (BDCM), dibromochloromethane (DBCM), and bromoform (TBM). The 195 limits of detection (LOD) were $0.13 \mu \mathrm{g} / \mathrm{L}$ for TCM and DBCM, and $0.11 \mu \mathrm{g} / \mathrm{L}$ for BDCM and TBM. 
196 Microbial analysis was conducted after the water was cultured onto selective media for the

197 detection and enumeration of total coliforms, E. coli, Enterococcus spp.,

198 Pseudomonas aeruginosa, and total viable counts (TVC) at $22{ }^{\circ} \mathrm{C}$ and $37^{\circ} \mathrm{C}$. The methods used

199 for the microbial analysis are presented in Supplementary Methods document.

200 All water samples were collected from the main faucet of the household used to satisfy their

201 potable needs and it was directly connected to the municipality's water supply.

202 Residual chlorine was measured with a portable photometer (MaxiDirect, Lovibond) in water

203 directly collected from the tap using the DPD (N,N-diethyl-p-phenylenediamine) method.

\section{Statistical analysis for the urban population study}

\section{Descriptive analysis of the questionnaire responses}

206 Descriptive statistics (i.e. means and standard deviation for the continuous variables, and

207 frequencies and percentage by category for the categorical variables) were calculated for the 208 responses to the questionnaire. The descriptives were grouped by category of question (i.e. 209 demographics and other background characteristics, drinking water habits and cleaning activities,

210 lifestyle and behavioral indicators, healthcare services access, health status, life in the 211 neighborhood) for the complete study population $(n=132)$.

\section{Descriptive analysis of the water indicators and water habits}

213 Descriptive statistics for the drinking-water THM and microbial counts were separately presented 214 for the samples collected directly from the tap when no filter was attached $(n=119)$ from those 13 215 samples that were collected with a filter present. When THM values were below the LOD ( $\mathrm{n}=4 \mathrm{for}$ 216 TCM and $n=1$ for TBM), they were imputed to LOD/2. The sum of all THM species (total THM) 217 and the sum of the brominated species (BrTHM; i.e. BDCM, DBCM, and TBM) were calculated. 218 For the statistical analysis of the microbial water quality we considered the presence or absence of 219 colonies for E. coli and Enterococcus spp. instead of the absolute count number (EU Council, 220 1998). For the coliforms, Pseudomonas aeruginosa, and TVC at 22 and $37^{\circ} \mathrm{C}$ presence or absence, 221 the percentage of samples with detected colonies were described. Specifically, for TVC at 22 and $22237^{\circ} \mathrm{C}$ a smaller number of samples was analyzed $(n=95)$ due to external contamination. For the 223 THM concentrations the descriptives included: mean, standard deviation (sd), median and 224 percentiles, i.e. $25^{\text {th }}, 95^{\text {th }}$ percentiles, and the range, i.e. min and max, while for the microbial 
225 analysis the frequency of samples with at least one CFU (and the percentage) was calculated. Water

226 samples collected from households $(n=13)$ having permanently connected point of use filters in

227 the main faucet were excluded from the main statistical analysis.

228 The results of the THM and microbial analyses were presented separately for the total THM, the

229 E. coli and the Enterococci spp., as they are considered of higher priority compared to the single

230 THM species and the other microbial indicators (e.g., coliforms).

\section{Mapping of the water and the quality of life indicators}

232 To evaluate how indicators pertaining to the water and quality of life are distributed in different

233 quarters of Limassol, we mapped a selection of urban indicators by quarter. For the water quality

234 indicators, the median levels of total THM, free chlorine, BrTHM per quarter were mapped, as

235 well as, the percentage of samples with detectable levels of coliforms and TVC. From the urban

236 questionnaire data, all indicators were mapped. However, for brevity, we present in the maps and

237 discuss select indicators per category for the following: (i) issues on access to health care services

238 due to delays and financial constraints, (ii) life in the neighborhood, and (iii) two indicators from

239 the category on access to green spaces to illustrate potential differences between quarters.

\section{Exploratory environment-wide association study (EWAS)}

241 We performed an exploratory environment-wide association study (EWAS) to agnostically 242 synthesize knowledge and concurrently investigate possible associations of the measured water 243 quality indicators and questionnaire-based socioeconomic, lifestyle and behavioral factors. This 244 exercise helped us to demonstrate how an EWAS approach can be incorporated in analyses that 245 are based upon the urban exposome framework. The outcomes used in the EWAS analysis were 246 three self-reported health status outcomes: (i) general health status, (ii) diagnosed with any chronic 247 disease, and (iii) diagnosed with any disease in the past year ("any disease the past year", i.e. 248 asthma, diabetes, allergies, hypertension, cardiovascular or respiratory illnesses, depression, 249 cancer, musculoskeletal problems) (Patel, Bhattacharya \& Butte, 2010). The EWAS analysis 250 included a correlation matrix between all variables, regression analysis, and a multi-omics-based 251 approach to describe correlations between all the variables measured accounting for specific health 252 outcomes. 
253 The variables included in the EWAS approach were divided in the following "blocks/groups" to 254 reflect different parameters of the human exposome, since the analysis was performed at the 255 individual level:

256

257

258

259

260

261

262

263

264

265

266

267

268

269

270

271

272

273

274

275

276

277

278

279

280

281

- Block/group 1 (specific external domain): water THM levels, free chlorine

- Block/group 2 (general external and internal domain): drinking water habits (e.g., number of glasses of water consumed by source)

- Block/group 3 (general external and internal domain): household cleaning activities (e.g. dishwashing, mopping, bathroom cleaning)

- Block/group 4 (general external domain): neighborhood quality of life (variables of "highest consensus": heath care access, life in the neighborhood and green urban spaces)

- Block/group 5 (internal domain): participant characteristics (e.g., age, sex, BMI)

- Block/group 6 (internal domain): self-reported diseases in the past year (e.g. asthma, diabetes, allergies, hypertension, cardiovascular or respiratory illnesses, depression, cancer, or musculoskeletal problems).

In all categorical variables the "I don't know/I don't want to answer" responses were re-coded to "missing". Then, scores were added per category (presented in Table S2) and used in statistical analysis when categorical variables could not be used (e.g. correlations).

In the preliminary correlation analysis, all variables (including the three outcomes) were used as continuous and the Spearman correlation coefficient was calculated without any transformations. The results were visualized with a correlation plot. Then, regression models were fitted. The variable for the general health status was used as continuous in linear regression whereas responses for self-reported chronic disease and any disease the past year were used as binary variables in logistic regression. The regression models were repeated after adjusting for age and sex. The continuous predictors were scaled and centered in all regression models. The p-values of all model parameters that were used for inference (i.e. excluding the intercept for the univariable models and excluding the intercept, age, and sex coefficients from the adjusted models) were summarized and corrected for Benjamini-Hoechberg false discovery rate (FDR). Only parameters with an FDRcorrected $\mathrm{p}$-value $<0.10$ separately applied to the univariate ( $\mathrm{n}=129$ tests) and the adjusted models $(\mathrm{n}=123$ tests) were considered statistically significant. 
282 In the last part of the EWAS analysis, we followed an approach used in multi-omics studies where

283 the variables are grouped and partial least squared discriminatory analysis (block PLS-DA) is

284 conducted to identify possible correlations between the variables of the different blocks accounting

285 for an outcome (Rohart et al., 2017). In this analysis, the predictor variables were used as

286 continuous and all outcomes were used as categorical. The correlations between the predictor

287 variables in blocks were presented in circular plots (circo plots) where positive and negative

288 Pearson pairwise connections are shown in the circle and lines indicate the levels of each variable

289 within each outcome category.

290 All analyses (regressions and block PLS-DA) were performed for the three outcomes using all the

291 blocks/groups as predictors except for the analysis for the outcome "any disease the past year".

292 This variable was created as the summary of the variables of block/group 6 (self-reported diseases

293 the past year). Thus, in this analysis, the separate diseases of block/group 6 were not included due

294 to their association with the outcome of "any disease the past year".

295 All analyses were conducted in R 3.5.1 with RStudio 1.1.423 (RStudio Team, 2015; R Core Team,

296 2017). Input data, the output, scripts and the questionnaires are available in the supplementary

297 material. The packages used in the analysis are listed in Table S3.

298 Results

299 Perceptions study results

300 Approximately, 10 municipality technical officers were approached for interviews and to fill in

301 the municipality questionnaire. In total, five interviews were conducted, and six questionnaires

302 were administered. The importance of climate change and its effects was pointed out by all

303 municipality officers during the face-to-face interviews and within the questionnaire responses. In

304 rating the environmental concerns (1 for very low and 5 for very high concern), water quality had

305 the lowest score with increasing order of scoring for soil contamination $<$ waste $<$ general chemical

306 exposures $<$ noise $<$ air pollution.

307 In total, 181 participants responded to the online questionnaire that was addressed to citizens and

$308134(74 \%)$ filled in the complete questionnaire. Ninety-one of the respondents reported living in

309 Limassol (35\% males and 65\% females) with a mean age of 35 years old [range: $18-77$ years old].

310 The majority (81\%) was born on Cyprus, and 13\% were born in another EU country, the rest (6\%)

311 were born in a non-EU country. As expected from the distribution of the questionnaire among the 
312 staff of the university, most of the respondents (84\%) were highly educated holding at least a

313 Bachelor's degree. Approximately half of the respondents were married (46\%) with children $314(47 \%)$.

315 Residents of urban Limassol ( $n=91)$ were mostly concerned about being severely exposed to air

316 pollution and noise (Table 1). Water quality ranked low while air pollution and noise ranked high

317 in the "severely exposed" category among all environmental exposures. Approximately 30\% of

318 the respondents reported that they were not exposed to water pollution or soil contamination, but

319 at the same time an equally high proportion of respondents reported "don't know", suggesting

320 inadequate knowledge about the drinking-water or soil quality in their city. With regards to water

321 quality, $81 \%$ reported worrying about chemical exposures, and $41 \%$ reported they were exposed

322 to chemicals daily.

323 Among all urban respondents, only $\sim 30 \%$ reported the consumption of tap water, while $32 \%$

324 reported treating the water before consumption (filtering or cooking), and 39\% mentioned not

325 drinking the tap water at all. Also, the "highest in importance" concerns of the citizens about tap

326 water quality were those associated with either chemicals $(47 \%)$, or microbes $(37 \%)$ and much

327 less concern was expressed about the taste (10\%).

328 Population study results

329 Background information and opinions

330 In total, 132 residents of the Limassol municipality answered the questionnaire and agreed to water

331 collection from their households' main tap. The distribution of the study participants by quarter

332 and the population can be found in Table S1. The mean age was 45.6 years and the majority were

333 females (62.1\%). Most of the participants were born in Cyprus [ $n=114(86.4 \%)]$ living there for

334 all their lives (Table 2, Table S4).

335 Most of the study participants reported being in very good or good health condition (46\% and $43 \%$,

336 respectively). However, 21\% reported having a chronic disease and 57\% reported at least one of

337 the following health conditions during the past year: asthma, cardiovascular diseases,

338 hypertension, diabetes, liver conditions, cancer, depression, or musculoskeletal problems (Table

339 3). With regards to access to health care, the main questions were about delays due to lack of

340 transportation or long waiting lists (Table S5). Lack of transportation did not seem to be a major

341 constraint to access health care centers among those that opted to answer; however, long waiting 
342 lists were reported by $11 \%$. To the question about financial constraints for health care access,

343 delays in dental care were most frequently mentioned (14\%). Most participants (64\%) reported

344 living close to green spaces, but a total of $63 \%$ also reported that these green spaces were not well-

345 maintained and there was a consensus for not using them. A summary of the responses about health

346 care access, lifestyle, the quality of life in the neighborhood and other urban topics can be found

347 in Table S5.

\section{Water quality indicators assessment of drinking water habits}

349 The main chemical water quality indicators assessed were THM. Only $2 \%$ of the households' tap 350 water exceeded the THM parametric value $(100 \mu \mathrm{g} / \mathrm{L})$. Results conforming with the parametric

351 values were also obtained for the microbial indicators monitored, i.e. E.coli and Enterococci spp.

352 All samples were within the parametric values (0 CFU per 100mL), except for one household 353 where Enterococci colonies were detected. Total coliforms were detected in 28 of the 132

354 households and Pseudomonas aeruginosa counts were detected in 5 out of the 132 households 355 (Tables 4 and 5).

356 The drinking-water consumption habits reported by the urban participants similarly reflected what 357 was already observed in the perceptions study (presented earlier) where only 30\% reported 358 consuming tap water and most participants reported a preference for The majority reported using 359 tap water in general, however bottled water use was noted by most respondents. The more 360 frequently reported single drinking water source was bottled water (30\%) followed by tap water 361 (22\%). A comparable proportion of the participants reported the combined use of tap water and

362 bottled water (Table 6). More than half of the study partipants reporting consuming less than one 363 glass of water per day from the tap (median number of glasses consumed from tap was 1 glass/day) 364 (Table 6).

\section{Mapping of urban indicators of water and quality of life}

366 The measured water quality indicators in each household were aggregated and mapped by quarter.

367 For the chemical water parameters, the mapped median total THM and the brominated species 368 (BrTHM) by quarter showed similar patterns (Figure 2). As the BrTHM are a subset of the total 369 THM, their median values by quarter were lower. The highest median THM values were observed 370 in the quarters located between the beachfront and the northern quarter of Agia Fylaxi (near the 
371 center of the city). Mapping of free chlorine levels followed an opposite pattern to THM, i.e. higher

372 levels of free chlorine in the seaside quarters and slightly higher in the northern quarter (being 373 closer to the main water treatment plant). The maximum median value of total THM was $63 \mu \mathrm{g} / \mathrm{L}$

374 and it was observed in the center of Limassol (quarter of Agios Georgios). In this quarter, the

375 median free chlorine levels were below detection. The range of the median total THMs by quarter

376 was $6-63 \mu \mathrm{g} / \mathrm{L}$ for the small quarters in the beachfront and behind the city port and the quarter of

377 Agios Georgios. The variability of the median free chlorine levels was smaller, ranging from below

378 detection to $0.4 \mathrm{mg} / \mathrm{L}$ in the quarters of Agia Zoni and Agia Trias (in the center and by the seafront,

379 respectively). A map with the quarter names of municipality of Limassol is available in

380 Supplementary Information (Figure S1).

381 With regards to the microbial parameters, as mentioned in the previous section, only one sample 382 had detectable colonies of Enterococcus spp. while E. coli was not detected at all. Thus, we 383 mapped only the percentage of samples found to be positive for coliforms or had detectable 384 heterotrophic bacteria (TVC at 22 and 37C) (Figure 3). In a one quarter, two of the three samples 385 analyzed were positive for coliforms and, therefore, it had the highest percentage of samples with 386 colonies. This quarter was geographically located in the zone with the highest median chlorine 387 levels $(0.3 \mathrm{mg} / \mathrm{L})$ (Figure 2, Figure 3).

Description and mapping of access to health care services, life in the neighborhood and use of green spaces

390 With regards to access to health care, most participants reported having issues with two major

391 parameters, i.e., long waiting lists and financial constraints to access dental care. From the

392 respective maps (Figure 4), participants living in the quarters of Katholiki, Agia Trias, Omonoia

393 and Agios Nektarios did not report any issues pertaining to access to health care. Whereas, other

394 quarters such as Agios Ioannis/Arnaoutogeitonia, Agia Zoni and Agios Nikolaos were more

395 consistently in the "mid-range" with $20 \%$ participants reporting issues for both indicators. With

396 regards to the question about having someone in the neighborhood to ask for help in emergencies,

397 overall, only 25/132 participants opted for the answers "I don't know" and "I disagree completely

398 or probably" (Figure 5). However, responses of strong agreement ("I completely agree" vs all the

399 other options from "I probably agree" to "I completely disagree") varied a lot across the quarters.

400 For example, in Agios Spyridonas only 20\% agreed that there is always someone to help them 
401 while in Agios Nikolaos 80\% (Figure 5). With regards to proximity and use of green space, most

402 participants from all quarters reported that they agree living near to green space but they do not 403 use it for activities (Figure 6). This is evident in quarters by the seafront and the largest quarter of 404 Agia Fylaxi/Panagia Evangelistria which is peripheral to the city the center and closer to less 405 densely populated areas.

406

407

408

409

410

411

412

413

414

415

416

417

418

419

420

421

422

423

424

425

426

427

428

429

430

\section{Exploring environment-wide associations within the municipality of Limassol}

A correlation plot between all variables used in the EWAS analysis (listed in Table S2) did not show any specific or unexpected patterns of correlation among the urban variables (Figure 7).

Notable correlations were observed among different variables of the same block/group. All THM compounds in drinking-water correlated well with each other and they were negatively correlated with free chlorine levels. Additionally, strong correlation was observed among the household cleaning variables (mopping, dishwashing and bathroom cleaning). The variables of the "cleaning" block/group (block/group 3) correlated also with certain health conditions, such as musculoskeletal problems (neck problems).

In the regression part of the EWAS analysis, a total of 129 predictors were summarized from the simple models and 123 predictors were used in the models adjusted for age and sex. These predictors include both parameters measured in water, i.e. THM, and questionnaire responses (summarized in Table S2). In the models adjusted for age and sex, four parameters had an FDRcorrected p-value $<0.1$, i.e., financial issues in access to dental care, depression, hypertension and asthma. Having encountered financial issues in access to dental care [n=18, (14.1\%) participants] and depression $[\mathrm{n}=3,(2.8 \%)$ participants) were statistically significant negative predictors for better general health status, while and higher odds of having a chronic disease were associated with hypertension and asthma $[n=19,(16.2 \%)$ and $n=10,(8.5 \%)$ participants, respectively]. In the univariate regression, in addition to the parameters that were significant in the adjusted models, musculoskeletal problems (i.e. neck and back problem) were associated with higher odds of having a chronic disease but not with the outcome of general health status. The parameters ranked by the FDR adjusted p-value can be found in Table S6.

The results of the second EWAS analysis and the correlation between the variables used in the PLS-DA models were summarized in the circular plots (circo plots) of Figure 8. Again, all three outcomes were used, however, the model for the chronic disease did not converge and thus, the 
431 plot is not presented. For the other two outcomes the associations between the variables were not 432 the same, as expected due to the difference in the outcomes between the two models. The THM 433 variables correlated with each other and with the household cleaning activities (i.e. dishwashing, 434 mopping, bathroom cleaning) as it was also shown in the simple correlation plots. The correlations 435 were less in number when the outcome was "any disease the past year" compared to the 436 correlations visualized in the circo plot of the "general health" as an outcome. Additionally, 437 different levels of the predictor variables were noted depending on the outcome, as it can be seen 438 by the lines on the outside perimeter of the circular plot. These lines, however, were not used for 439 interpretation due to the study's exploratory nature to avoid any misleading inferences.

\section{Discussion}

442 In this proof of concept study of the urban exposome, we used an interdisciplinary approach to 443 identify trends in perceptions about environmental exposures and how they correlated with the 444 spatially-resolved drinking-water quality trends of chemical and microbial indicators for the municipality of Limassol during the hot season (summer). Quality of life indicators (e.g. access to green spaces, the life in the neighborhood and reasons for delay or financial constraint in access to health care) were mapped at the level of the quarter (smallest administrative unit). No clear disparities at the quarter level were observed for all neighborhood-based queries, but financial constraints, especially for dental care were noted. Additionally, we generated global linkages and correlations between the health status of urban participants and their environmental/lifestyle/behavioral exposures at the individual level. A total of 129 parameters from 36 variables either directly measured in water (water quality) or derived from the survey (quality of life in the city) were integrated using an exploratory, agnostic, exposome-based EWAS approach. The general health and chronic health status of the urban participants were significantly associated in regression analysis with different health outcomes (e.g. hypertension, asthma) and quality of life indicators (e.g. financial issues in access to dental care). Circular correlation plots were derived from 36 urban exposome variables which were divided in six groups and accounted for self-reported health indicators (general health and having any diseases the past year). This study is an application of the urban exposome framework and the first to generate a snapshot of the actual urban exposome of Limassol, Cyprus, with a focus on water and quality of life indicators. 
462 Urbanization, migration and other drivers of societal changes in urban settings are shaping 463 population health and quality of life in cities leading to interventions such as the large scale 464 neighborhood renewal programs that aim to improve living conditions and quality of life in cities 465 (Kramer et al., 2017). The impact of such neighborhood-based programs could be enhanced with 466 the comprehensive assessment of environmental, economic, societal and other health parameters 467 in the city. Within the context of improving urban life, novel paradigms such as the exposome can 468 be adapted to provide a more interdisciplinary approach in tackling urban problems. The urban 469 exposome can be viewed simply as the totality of environmental exposures occurring in cities 470 (Probst-Hensch, 2017; Robinson et al., 2018). However, this definition is rather centered on 471 individuals and it does not include wider determinants of urban health. For example, a recent study 472 described the human exposome in city-based cohorts and focused on specific exposure-effect 473 associations in one or multiple cohorts being pooled together (Robinson et al., 2018). In this study, 474 we propose a novel approach using the urban exposome as a study framework to describe 475 systematically how broader urban characteristics can be evaluated with an interdisciplinary 476 methodology. Thus, we have placed the city and its smaller areas as the measurable units in the 477 center of this exposome approach. Moreover, we have used the perceptions and the urban 478 population study as two sources of information that can be summarized to provide a snapshot of 479 the urban exposome of Limassol focused on water and quality of life.

480 The case of water pollution and the provision of safe and clean water to urban dwellers presents 481 one of the most challenging elements to be incorporated within the urban exposome framework. 482 This might be due to the complex systems that drive water quality and water choices given also 483 the aging water infrastructure in urban settings. These challenges are also evident in the literature 484 and in studies of water quality indicators but their links with the exposome are scarce. To our 485 knowledge, the literature in exposome approaches to evaluate water quality is limited and it has 486 not focused on the urban environment or the general population. For example, using an 487 environment-wide association study methodology, the pregnancy exposome study on the INMA488 Sabadell Birth Cohort in Spain looked into modeled at the individual level water disinfection 489 byproducts (THM), among a wider set of other exposures ranging from urinary markers of 490 chemical exposures to air pollution and noise (Robinson et al., 2015). They showed that the three 491 THM "classes" studied (total and brominated THM, and chloroform) were strongly correlated 492 with each other, but not with the other environmental exposures (Robinson et al., 2015). Albouy- 
493 Llaty et al (2016) explored the association between endocrine disruptors (atrazine metabolites and

494 nitrate/atrazine mixture) in drinking water and preterm birth accounting for socioeconomic factors

495 (deprivation index) in the Poitou-Charentes region of France (Albouy-Llaty et al., 2016). The

496 exposure to atrazine and the nitrate/atrazine mixture at the individual level was inferred from

497 routine community monitoring of water quality; preterm birth was found to be associated with the

498 deprivation index at the level of the neighborhood but not with the exposure to atrazine

499 metabolites. Exposure to atrazine (measured through the metabolite 2-hydroxyatrazine) was not

500 found to be a significant risk factor for preterm birth when accounting for the socioeconomic status

501 of the area (Albouy-Llaty et al., 2016).

502 This is the first application of the urban exposome framework that took place in a medium-sized

503 European city, Limassol, Cyprus. We used an agnostic approach following the urban exposome

504 framework and we described water quality indicators at the level of quarter (the smallest

505 administrative area within a municipality), accounting for urban, general population characteristics

506 and additionally including the opinions/perceptions of residents and municipality technical

507 stakeholders. The analysis included a suite of water quality aspects (chemical and microbial) which

508 belong to the internal domain of the urban exposome and the specific external domain of the human

509 exposome, and stakeholders' opinions about environmental issues (specific external urban

510 exposome and general external human exposome). Moreover, quality of life was assessed through

511 citizens' answers about access to healthcare and green spaces, and it was included along with

512 lifestyle/behavior, and demographics in the EWAS analysis. This analysis is part of developing

513 the urban exposome profile of Limassol and provides a snapshot of the state of the city, which will

514 be combined with analysis of routinely collected.

515 As mentioned before, our study aimed to provide a methodological approach in a relatively small

516 city. Therefore, the generated associations of different health outcomes and quality of life

517 indicators with general health or with having a chronic disease in the EWAS study should be

518 interpreted with caution due to the lack of adequate statistical power. In our case, the EWAS

519 analysis is limited by the data at hand but, it is more of exploratory nature, as it is a part of this

520 proof of concept study. Previous EWAS-exposome studies have been broader, with larger sample

521 sizes, and, thus, more power (Patel \& Manrai, 2014).

522 One observation that stood out in the correlation analysis is the negative association of water THM

523 with cleaning activities. Previous studies have shown positive correlations between cleaning 
524 activities and urinary THM levels, and not between water THM levels and cleaning activities

525 (Charisiadis et al., 2014). However, our observation, taking into consideration previous work on 526 the exposure assessment to disinfection byproducts (Gängler et al., 2018), indicates the 527 complexity of exposure assessment using environmental measurements as proxies of exposure, 528 especially in EWAS studies. The inclusion of the perceptions study in developing the urban exposome profile of Limassol, with the use of a qualitative and quantitative approach allowed

530 important community concerns about their urban life to surface. Air pollution was ranked as the 531 most significant concern among the study respondents. Besides the general interest of air pollution 532 and its health effects, Cyprus experiences frequent dust storms ("WHO | Ambient air pollution"; 533 Achilleos et al., 2014). These events have probably triggered a specific concern among the 534 population making air pollution the most frequently reported environmental concern in our study. 535 Overall, the results presented here, should be interpreted with caution because of limitations in the 536 study design (i.e. the cross-sectional design) and the small sample size or possible sampling bias 537 (especially in the perceptions study).

538 This proof-of-concept study aimed to showcase the utility of the urban exposome framework in a 539 urban study setting extending the continuum of the human exposome concept, thus, providing the 540 methodological background for future studies. We were able to demonstrate the use of different 541 tools in an integrative and interdisciplinary approach to capture the baseline urban exposome of 542 Limassol municipality in this case. The same approach can be generalized. For example, if applied 543 to other urban dwellings with bigger sample, it will allow us to scale up the application of such 544 integrative and multidisciplinary protocols and will allow for the wider transfer and 545 generalizability of the results. Future studies should also incorporate a more comprehensive 546 assessment of urban quality of life (Serag El Din et al., 2013). In this analysis, the indicators of 547 quality of life were limited to life in the neighborhood or the use of green space and the 548 questionnaires were based on indicators previously assessed in larger urban studies which had not 549 included Cypriot cities ("EURO-URHIS2"; Pope et al., 2016). Additional information about social 550 life is available from this study population and it will be incorporated the urban exposome of 551 Limassol. Next steps will incorporate the analysis of routinely collected data of the registries and 552 human biomonitoring analyses in a more complete characterization of the urban exposome in 553 Limassol city. Moreover, given the "stakeholders" assessment of environmental problems, we 554 have moved on with air quality measurements throughout the municipality, which were conducted 
555 in the spring of 2018 while we explore how the routinely collected data from the one governmental 556 station for air quality measurements can be also included. This study shows how the goal of 557 developing the urban exposome framework can be achieved by using all the available information 558 in a real-time assessment of urban health and provide a tool for decision-making to stakeholders.

559 Our analysis did not raise any specific concerns about the quality of tap drinking water at the urban 560 quarter scale of Limassol city using both chemical and microbial indicators. It was shown however, 561 that residents do not trust, in general, the tap water and opt for using bottled water or water from 562 other sources such as the "vending machine" water (groundwater from mountainous wells) which 563 is very common practice in Cyprus. The cost of tap water is lower compared to bottled or "vending 564 machine" water and, thus, it may pose additional burden to household budgets, as it has been 565 shown in other studies (Massoud et al., 2013). Mapping the cost of water by quarter would likely 566 be informative about the existence or not of differences within Limassol in the economic burden 567 of water consumption. Urban green space was particularly noted for being close to participants' 568 households, however, limited use of such green spaces (e.g. parks) was reported. Both aspects of 569 access to health care and the use of green spaces within Limassol, were studied for the first time. 570 Our approach could form the basis for future targeted and more integrative urban studies on these 571 topics.

572 In general, our first results on the application of the urban exposome are promising and in need for 573 verification and expansion. First and foremost, given the different habits of the citizens, exposome 574 studies need to be more inclusive in the assessment of different water sources. Besides the 575 inclusion of standard water testing parameters, future studies should address participant 576 perceptions which are linked to behaviors, and, thus, exposures. Developing the health profile of 577 a city in urban exposome terms and integrating different approaches comes with several 578 limitations. Spatio-temporal considerations should be accounted for the dynamic nature of urban 579 exposome profiling. Although enough to estimate the background levels of population exposures 580 to chemicals, the relatively small sample size might have not allowed us to capture spatial 581 differences of the indicators measured within the smaller city administrative units. Additionally, 582 the lack of biomonitoring data on water-related exposures (i.e. to disinfection byproducts in urine) 583 have hindered the full deployment of EWAS tool capabilities. However, the availability of urine 584 biospecimen for this survey will allow us to use biomonitoring and untargeted metabolomics tools 585 in a follow-up manuscript. 
586 Conclusions

587 Developing sustainable city health profiles with the aid of the urban exposome framework is a 588 novel approach, yet, far from being simple or reductionistic in approach. It demands a 589 comprehensive characterization of relevant indicators ranging from drinking water quality to 590 health perceptions and opinions collected from the general population and technical stakeholders, 591 etc. The urban exposome framework and its application will pave the way for developing the next 592 innovative solutions and public health interventions for the city. This proof of concept case study 593 of the urban exposome in Limassol, Cyprus demonstrates the feasibility of using novel exposome 594 approaches in studying the city and its smaller within-city areas (quarters) as the units of reference. 595 Within this context, the absolute water quality indicators, city residents' and other stakeholders' 596 opinions need to be integrated and expanded along with exposomic profiles, such as metabolomics 597 or other -omics platforms and human biomonitoring protocols.

598 Thus, we need to develop specific urban exposome studies where city-specific characteristics and 599 within-city interactions and networks, can be used to redefine city health profiles. Evidence-based 600 and city-specific studies will help authorities reach informed decisions about everyday life, about 601 city infrastructure changes and their effects on urban health and personal exposures. This will help 602 the interpretation of inter-city difference and will allow the timely evaluation of within-city 603 challenges.

604

605

606

607

\section{Acknowledgements}

609 We would like to thank the Municipality of Limassol and all the study participants. Special thanks 610 to Ms. Andriana Till for her contribution to participant recruitment and to Dr. Stephanie Gaengler 611 for the fruitful discussions during data analysis. We would also like to express our gratitude to Drs. 612 Athos Agapiou and Diofantos Hadjimitsis for sharing the map templates for the quarters of 613 Limassol.

614 


\section{References}

616 Achilleos S, Evans JS, Yiallouros PK, Kleanthous S, Schwartz J, Koutrakis P. 2014. PM10 concentration levels at an urban and background site in Cyprus: the impact of urban sources and dust storms. Journal of the Air \& Waste Management Association 64:1352-1360.

619 Albouy-Llaty M, Limousi F, Carles C, Dupuis A, Rabouan S, Migeot V. 2016. Association 620 between Exposure to Endocrine Disruptors in Drinking Water and Preterm Birth, Taking Neighborhood Deprivation into Account: A Historic Cohort Study. International Journal

Andra SS, Austin C, Wright RO, Arora M. 2015. Reconstructing pre-natal and early childhood exposure to multi-class organic chemicals using teeth: Towards a retrospective temporal exposome. Environment International 83:137-145. DOI: 10.1016/j.envint.2015.05.010.

Andrianou XD, Makris KC. 2018. The framework of urban exposome: Application of the exposome concept in urban health studies. Science of The Total Environment 636:963-967. DOI: $10.1016 /$ j.scitotenv.2018.04.329.

Becker K, Seiwert M, Casteleyn L, Joas R, Joas A, Biot P, Aerts D, Castaño A, Esteban M, Angerer J, Koch HM, Schoeters G, Hond ED, Sepai O, Exley K, Knudsen LE, Horvat M, Bloemen L, Kolossa-Gehring M. 2013. A systematic approach for designing a HBM Pilot Study for Europe. International Journal of Hygiene and Environmental Health. DOI: 10.1016/j.ijheh.2013.07.004.

Buck Louis GM, Smarr MM, Patel CJ. 2017. The Exposome Research Paradigm: An Opportunity to Understand the Environmental Basis for Human Health and Disease. Current environmental health reports 4:89-98. DOI: 10.1007/s40572-017-0126-3.

637 Charisiadis P, Andra SS, Makris KC, Christodoulou M, Christophi C, Kargaki S, Stephanou E. 638 2014. Household cleaning activities as non-ingestion exposure determinants of urinary 
trihalomethanes. Environmental Science \& Technology 48:770-780. DOI: 10.1021/es404220z.

641 Charisiadis P, Andra SS, Makris KC, Christophi CA, Skarlatos D, Vamvakousis V, Kargaki S, Stephanou EG. 2015. Spatial and seasonal variability of tap water disinfection by-products within distribution pipe networks. The Science of the Total Environment 506-507:26-35. DOI: $10.1016 /$ j.scitotenv.2014.10.071.

Cui Y, Balshaw DM, Kwok RK, Thompson CL, Collman GW, Birnbaum LS. 2016. The Exposome: Embracing the Complexity for Discovery in Environmental Health. Environmental Health Perspectives 124:A137-A140. DOI: 10.1289/EHP412.

Dai D, Prussin AJ, Marr LC, Vikesland PJ, Edwards MA, Pruden A. 2017. Factors Shaping the Human Exposome in the Built Environment: Opportunities for Engineering Control. Environmental Science \& Technology 51:7759-7774. DOI: 10.1021/acs.est.7b01097.

Elm E von, Altman DG, Egger M, Pocock SJ, Gøtzsche PC, Vandenbroucke JP. 2007. The Strengthening the Reporting of Observational Studies in Epidemiology (STROBE) statement: guidelines for reporting observational studies. The Lancet 370:1453-1457. DOI: 10.1016/S0140-6736(07)61602-X.

Escher BI, Hackermüller J, Polte T, Scholz S, Aigner A, Altenburger R, Böhme A, Bopp SK, Brack W, Busch W, Chadeau-Hyam M, Covaci A, Eisenträger A, Galligan JJ, GarciaReyero N, Hartung T, Hein M, Herberth G, Jahnke A, Kleinjans J, Klüver N, Krauss M, Lamoree M, Lehmann I, Luckenbach T, Miller GW, Müller A, Phillips DH, Reemtsma T, Rolle-Kampczyk U, Schüürmann G, Schwikowski B, Tan Y-M, Trump S, Walter-Rohde S, Wambaugh JF. 2016. From the exposome to mechanistic understanding of chemicalinduced adverse effects. Environment International. DOI: 10.1016/j.envint.2016.11.029. 
662 EU Council. 1998. Council Directive 98/83/EC of 3 November 1998 on the quality of water 663 intended for human consumption.

664 EURO-URHIS2. Available at http://results.urhis.eu/Default.aspx (accessed June 30, 2018).

665 Gängler S, Makris KC, Bouhamra W, Dockery DW. 2018. Coupling external with internal 666 exposure metrics of trihalomethanes in young females from Kuwait and Cyprus. Journal 667 of Exposure Science and Environmental Epidemiology 28:140-146. DOI: 668 10.1038/jes.2017.27.

669 Kramer D, Lakerveld J, Stronks K, Kunst AE. 2017. Uncovering How Urban Regeneration 670 Programs May Stimulate Leisure-time Walking Among Adults in Deprived Areas: A Realist Review. International Journal of Health Services 47:703-724. DOI:

Massoud MA, Maroun R, Abdelnabi H, Jamali II, El-Fadel M. 2013. Public perception and 674 economic implications of bottled water consumption in underprivileged urban areas. Environmental Monitoring and Assessment 185:3093-3102. DOI: 10.1007/s10661-0122775-x.

National Research Council. 2012. Exposure Science in the 21st Century: A Vision and a Strategy. DOI: $10.17226 / 13507$.

Patel CJ, Bhattacharya J, Butte AJ. 2010. An Environment-Wide Association Study (EWAS) on 680 Type 2 Diabetes Mellitus. PLoS ONE 5:e10746. DOI: 10.1371/journal.pone.0010746.

681 Patel CJ, Manrai AK. 2014. Development of exposome correlation globes to map out environment682 wide associations. In: Biocomputing 2015. Kohala Coast, Hawaii, USA: WORLD 683 SCIENTIFIC, 231-242. DOI: 10.1142/9789814644730_0023. 
684 Pope D, Puzzolo E, Birt C, Guha J, Higgerson J, Patterson L, van Ameijden E, Steels S, Owusu

685

686

687

688

689

690

691

692

693

694

695

696

697

698

699

700

701

702

703

704

705

MW, Bruce N, Verma A. 2016. Collecting standardised urban health indicator data at an individual level for adults living in urban areas: methodology from EURO-URHIS 2. European Journal of Public Health. DOI: 10.1093/eurpub/ckv220.

Population

Census

2011.

2014.

Available

at http://www.mof.gov.cy/mof/cystat/statistics.nsf/census-2011_cystat_en/census2011_cystat_en?OpenDocument (accessed September 9, 2014).

Probst-Hensch N. 2017. Happiness and its molecular fingerprints. International Review of Economics 64:197-211. DOI: 10.1007/s12232-017-0269-4.

R Core Team. 2017. R: A Language and Environment for Statistical Computing. Vienna, Austria: R Foundation for Statistical Computing.

Robinson O, Basagaña X, Agier L, de Castro M, Hernandez-Ferrer C, Gonzalez JR, Grimalt JO, Nieuwenhuijsen M, Sunyer J, Slama R, Vrijheid M. 2015. The Pregnancy Exposome: Multiple Environmental Exposures in the INMA-Sabadell Birth Cohort. Environmental Science \& Technology 49:10632-10641. DOI: 10.1021/acs.est.5b01782.

Robinson O, Tamayo I, de Castro M, Valentin A, Giorgis-Allemand L, Hjertager Krog N, Marit Aasvang G, Ambros A, Ballester F, Bird P, Chatzi L, Cirach M, Dèdelè A, DonaireGonzalez D, Gražuleviciene R, Iakovidis M, Ibarluzea J, Kampouri M, Lepeule J, Maitre L, McEachan R, Oftedal B, Siroux V, Slama R, Stephanou EG, Sunyer J, Urquiza J, Vegard Weyde K, Wright J, Vrijheid M, Nieuwenhuijsen M, Basagaña X. 2018. The Urban Exposome during Pregnancy and Its Socioeconomic Determinants. Environmental Health Perspectives 126:077005. DOI: 10.1289/EHP2862. 
706 Rohart F, Gautier B, Singh A, Lê Cao K-A. 2017. mixOmics: An R package for 'omics feature 707 selection and multiple data integration. PLoS computational biology 13:e1005752. DOI: $708 \quad$ 10.1371/journal.pcbi.1005752.

709 Rojas P, Neutra R. 2008. Stakeholder and participant involvement. In: Environmental Epidemiology. New York: Oxford University Press, 296-299.

711 RStudio Team. 2015. RStudio: Integrated Development Environment for R.

712 Samaniego L, Thober S, Kumar R, Wanders N, Rakovec O, Pan M, Zink M, Sheffield J, Wood EF, Marx A. 2018. Anthropogenic warming exacerbates European soil moisture droughts. Nature Climate Change 8:421-426. DOI: 10.1038/s41558-018-0138-5.

715 Serag El Din H, Shalaby A, Farouh HE, Elariane SA. 2013. Principles of urban quality of life for a neighborhood. HBRC Journal 9:86-92. DOI: 10.1016/j.hbrcj.2013.02.007.

717 Statistical Service - Population and Social Conditions - Health - Announcements - Survey Results: European Health Interview Survey, 2014. Available at http://www.mof.gov.cy/mof/cystat/statistics.nsf/All/4DE6CF465BC4DDCAC2258068003 72D29? OpenDocument\&sub=3\&sel=1\&e=\&print (accessed July 14, 2018).

721 Statistics on European cities - Statistics Explained. Available at 722 http://ec.europa.eu/eurostat/statistics-explained/index.php/Statistics_on_European_cities (accessed February 3, 2017). http://www.worldbank.org/en/topic/urbandevelopment/overview\#3 (accessed July 9, 726 2018). http://www.who.int/airpollution/ambient/health-impacts/en/ (accessed August 5, 2018). 
729 Wild CP. 2005. Complementing the Genome with an "Exposome": The Outstanding Challenge of 730 Environmental Exposure Measurement in Molecular Epidemiology. Cancer Epidemiology 731 Biomarkers \& Prevention 14:1847-1850. DOI: 10.1158/1055-9965.EPI-05-0456.

732 Zhang XQ. 2011. The economic role of cities. Nairobi: United Nations Human Settlements 733 Programme. 
Figure 1

\section{Urban exposome - human exposome continuum, and the practical application of the urban exposome framework in the urban setting of Limassol city.}

The parts of the urban exposome specifically discussed in the current analysis include a perceptions study and an urban population study, which includes parameters measured in drinking-water to assess the water quality coupled with questionnaire responses about individual lifestyle, behavioral, and personal health indicators.

Urban exposome domains (unit of reference: cities and within-city areas) and continuum with the human exposome domains

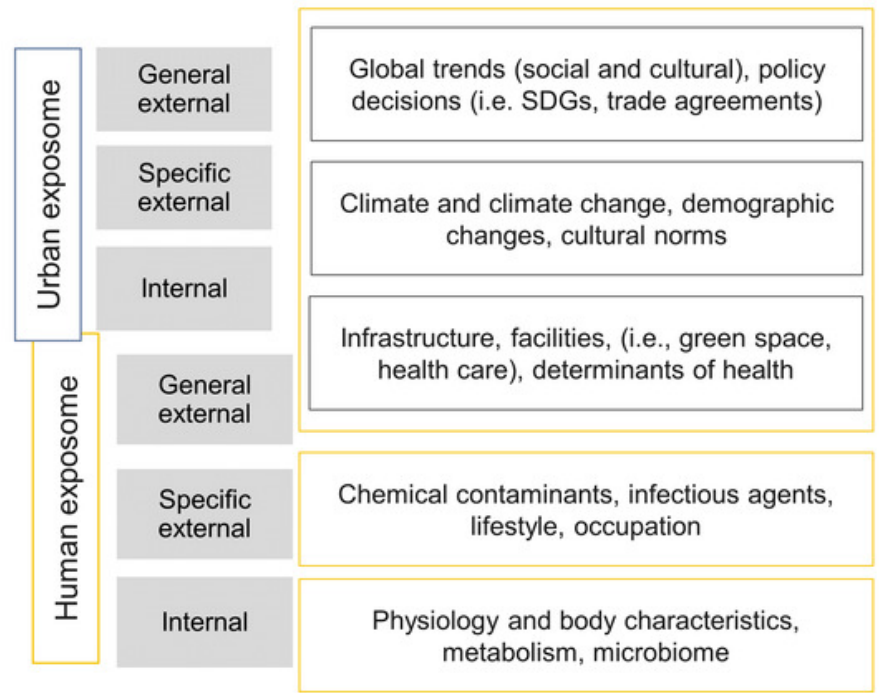

Application of the urban exposome in Limassol, Cyprus

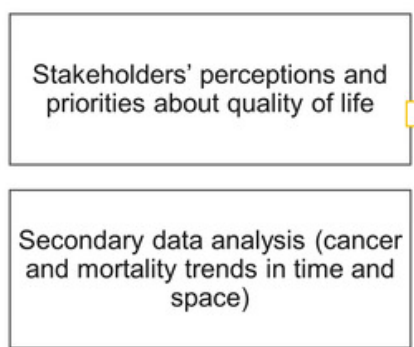

Population survey and biomonitoring study

Water quality, infrastructure use, habits and health status

Biomarkers of environmental exposures

Untargeted metabolomics
Drinking water and quality of life

Perceptions study

- Citizens and municipality officials

- Climate change effects

- Environmental concerns

- Drinking water quality use and opinions

- General perceptions of exposures

Urban population study

- Demographics

- Tap water parameters Disinfection byproducts Microbial analysis

- Water use

- Life in the neighborhood (contacts, green space use)

- Socioeconomic status (education, job status, healthcare access) 


\section{Figure 2}

Maps of the median water total THM, BrTHM and free chlorine levels by quarter within the municipality of Limassol, Cyprus (2017).

A. Total THM $(n=119)$

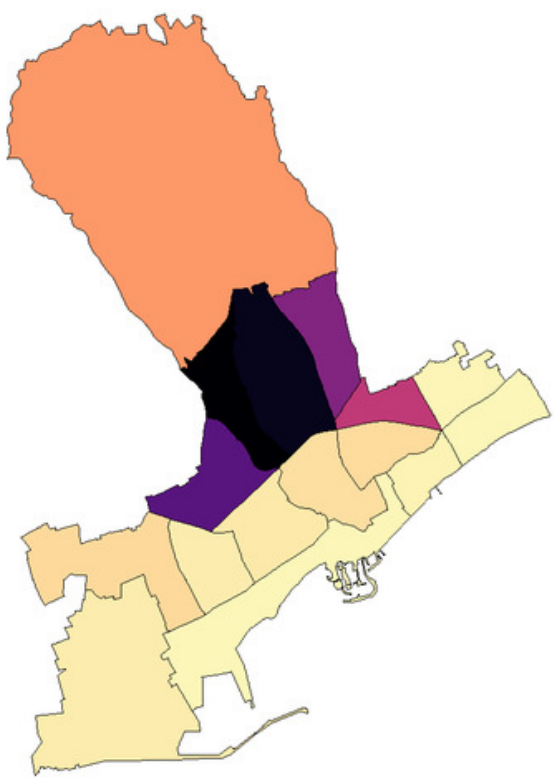

B. Brominated THM $(n=119)$

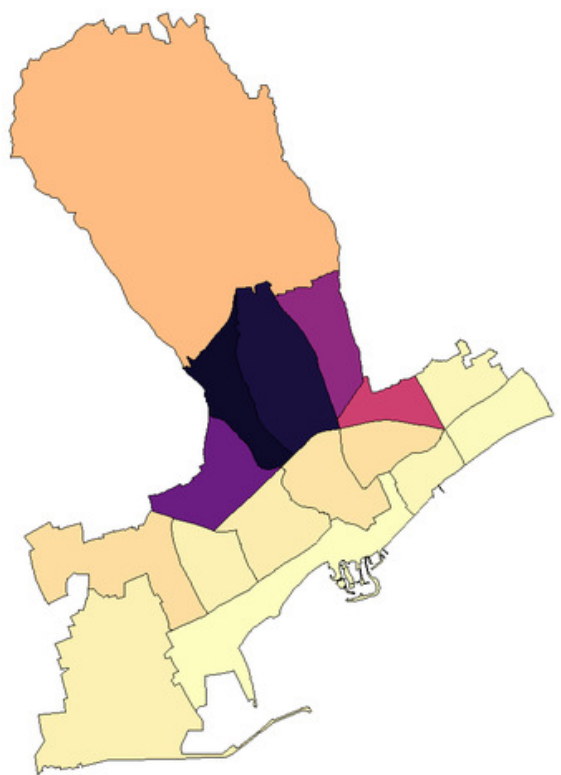

Median by quarter $(\mu \mathrm{g} / \mathrm{L})$

40

60

C. Free chlorine $(n=119)$

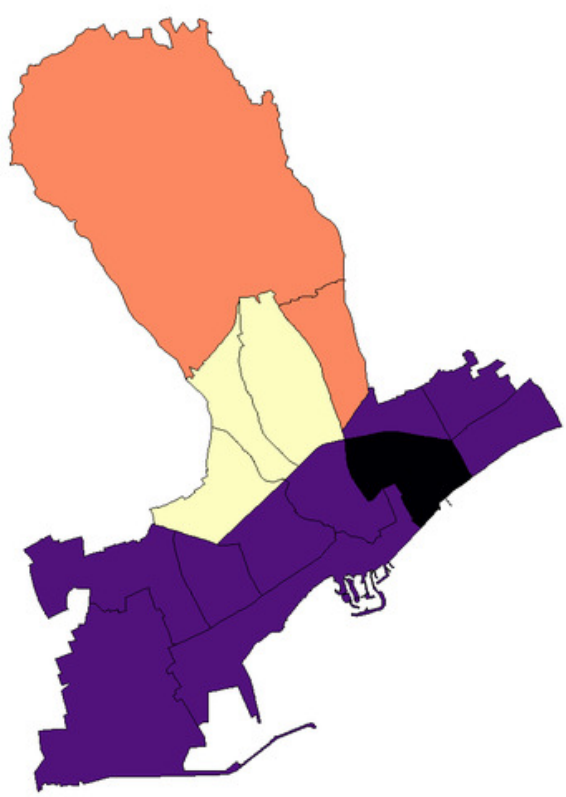

Median by quarter $(\mathrm{mg} / \mathrm{L})$

$\begin{array}{lllll}0.0 & 0.1 & 0.2 & 0.3 & 0.4\end{array}$




\section{Figure 3}

Maps of the percentage of samples with detectable counts of the monitored microbial parameters by quarter within the municipality of $\{$ Limassol, Cyprus (2017).

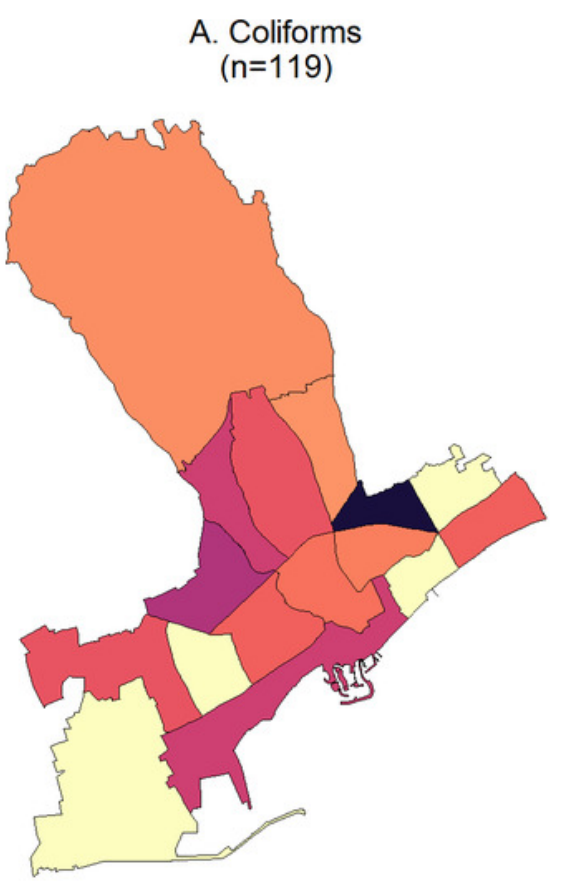

B. Total viable counts $22 \mathrm{C}(\mathrm{n}=86)$
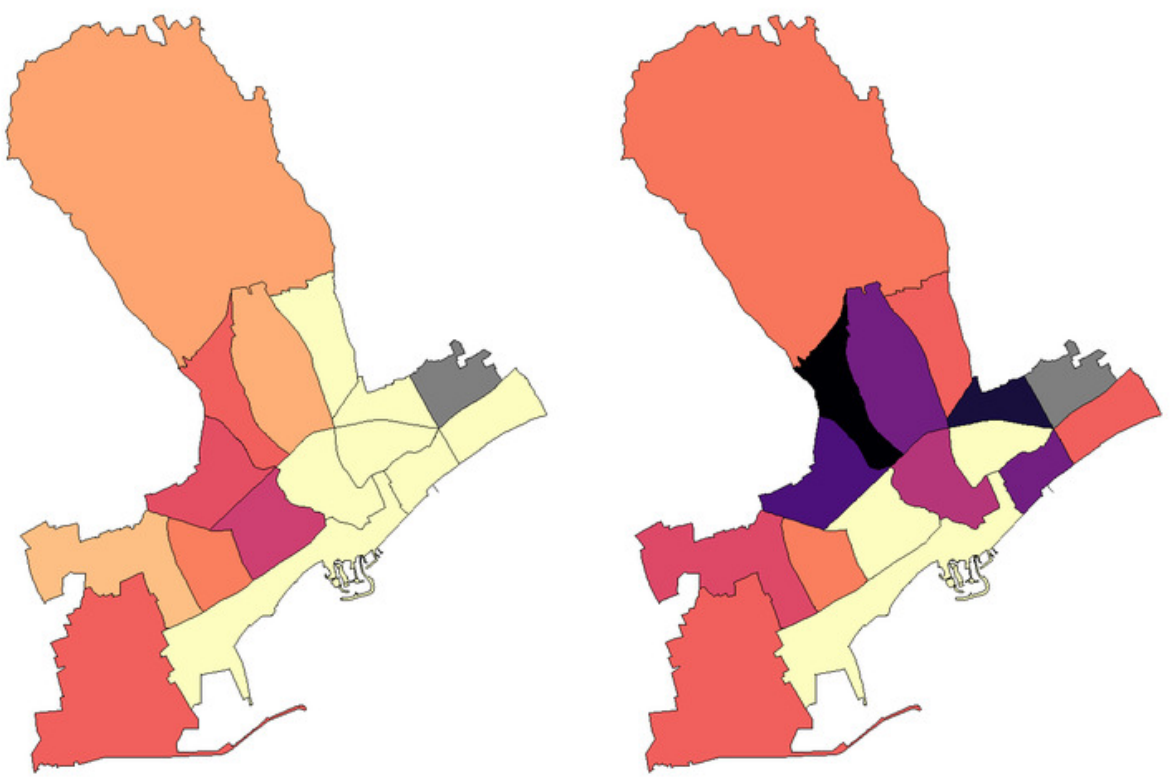

$\%$ samples with detected counts by quarter

$\begin{array}{llll}0 & 20 & 40 & 60\end{array}$ 


\section{Figure 4}

Percentage of study participants reporting constraints in access to health care by quarter of the Limassol municipality, Cyprus (2017).

A. Financial issues in access to dental care

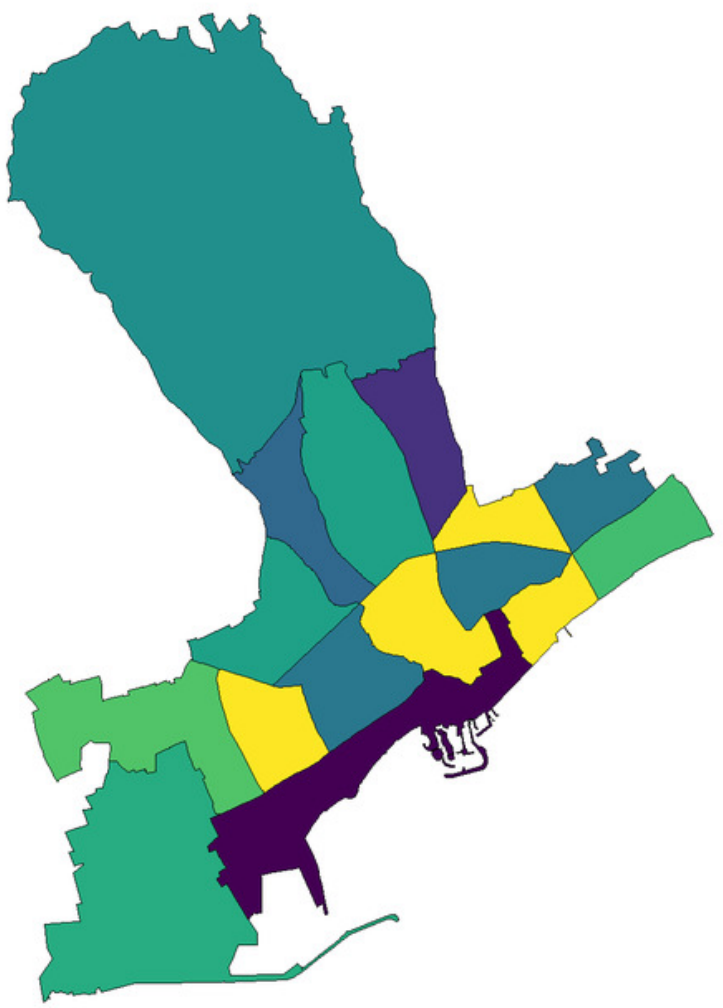

B. Delays due to long waiting lists

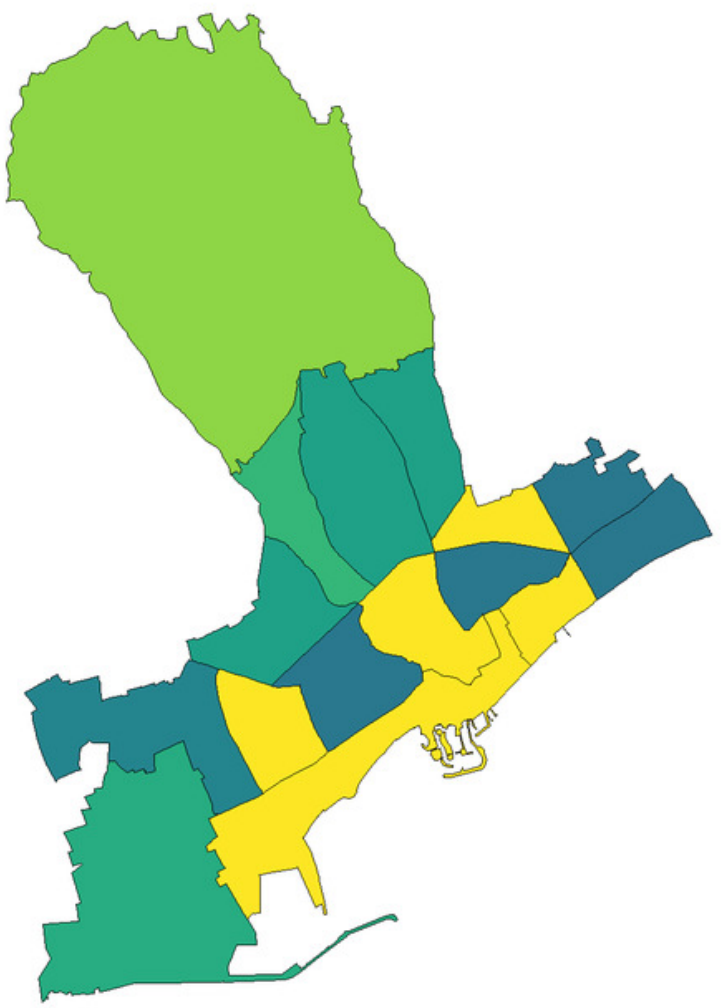

$\%$ participants by quarter

$0 \quad 10 \quad 20 \quad 30$




\section{Figure 5}

Percentage of study participants agreeing with different statements about life in the neighborhood by quarter of the Limassol municipality, Cyprus (2017).

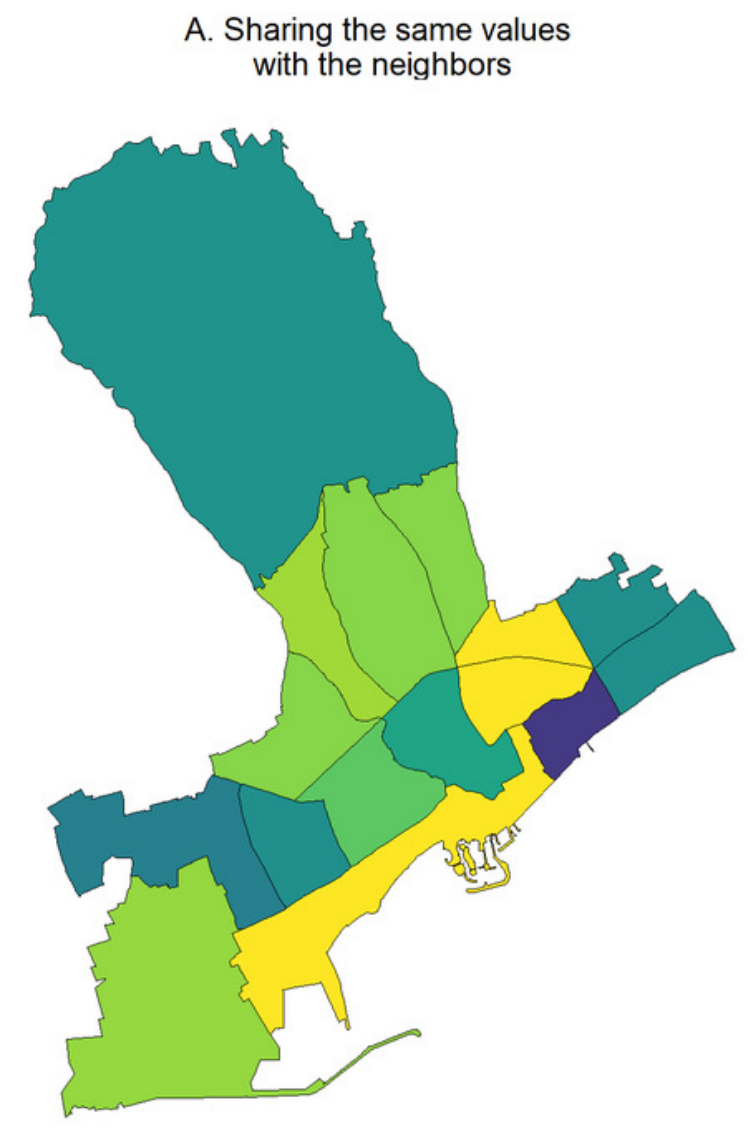

B. There is always someone to help in the neighborhood

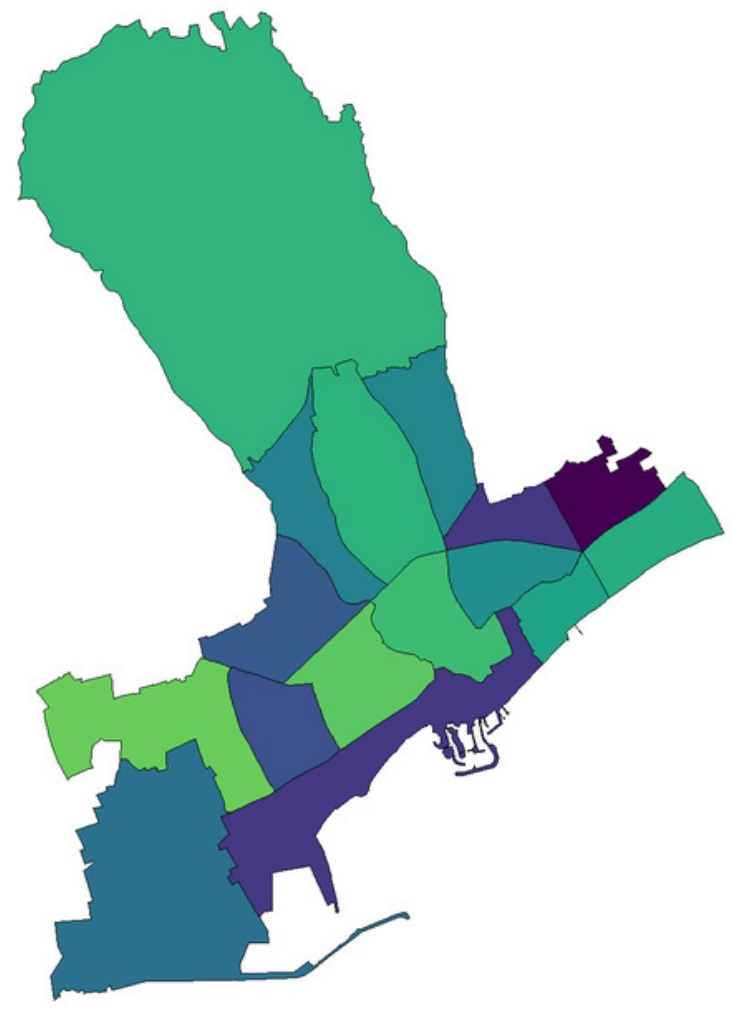

$\%$ participants by quarter

$\begin{array}{lllll}0 & 20 & 40 & 60 & 80\end{array}$




\section{Figure 6}

Maps by quarter of the percentage of study participants within the quarters of Limassol municipality, Cyprus (2017) agreeing the statements about access to green spaces.

A. Proximity to green space

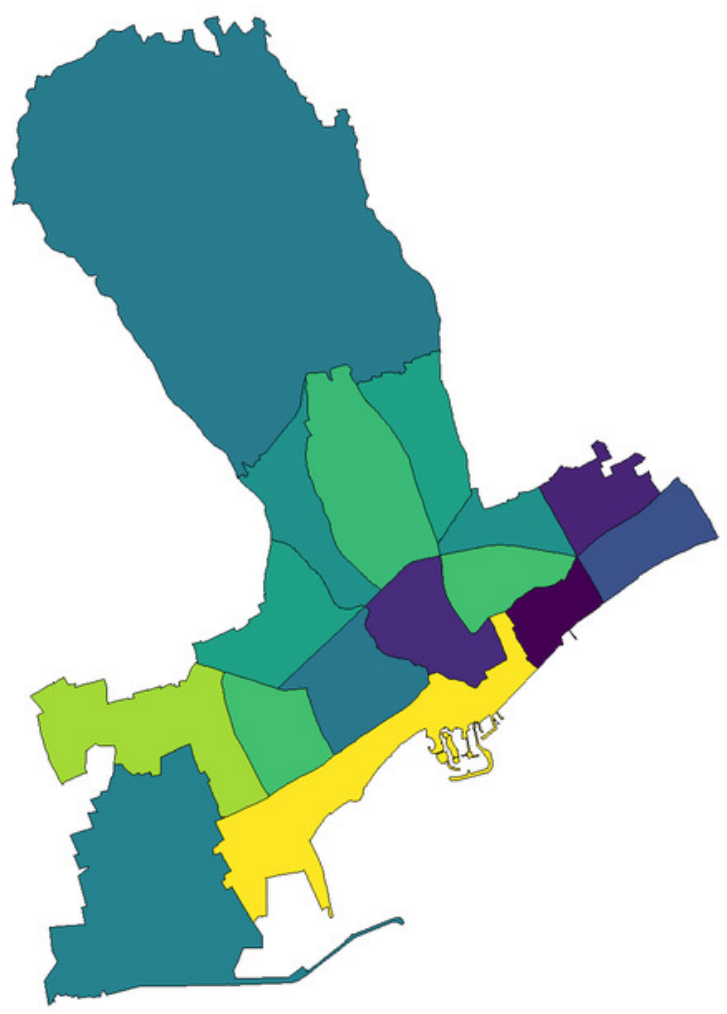

B. Doing activities in the green space nearby

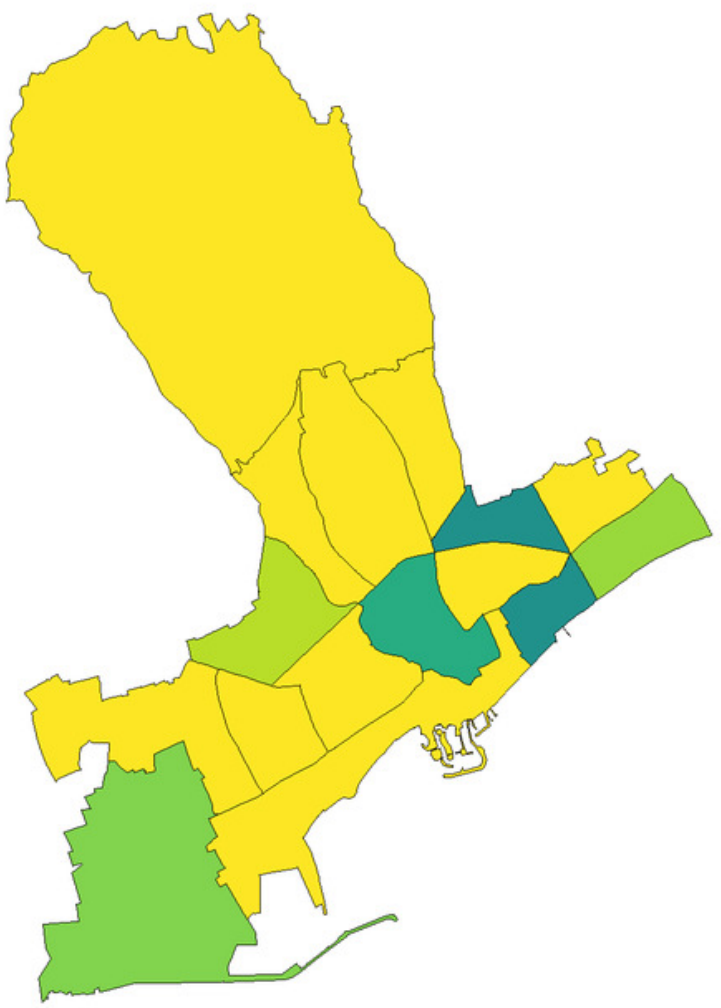

$\%$ participants by quarter

$0 \quad 20 \quad 40 \quad 60$


Figure 7

Correlation plot (Spearman correlation coefficient) for all the variables used in the environment-wide association exploratory analysis.

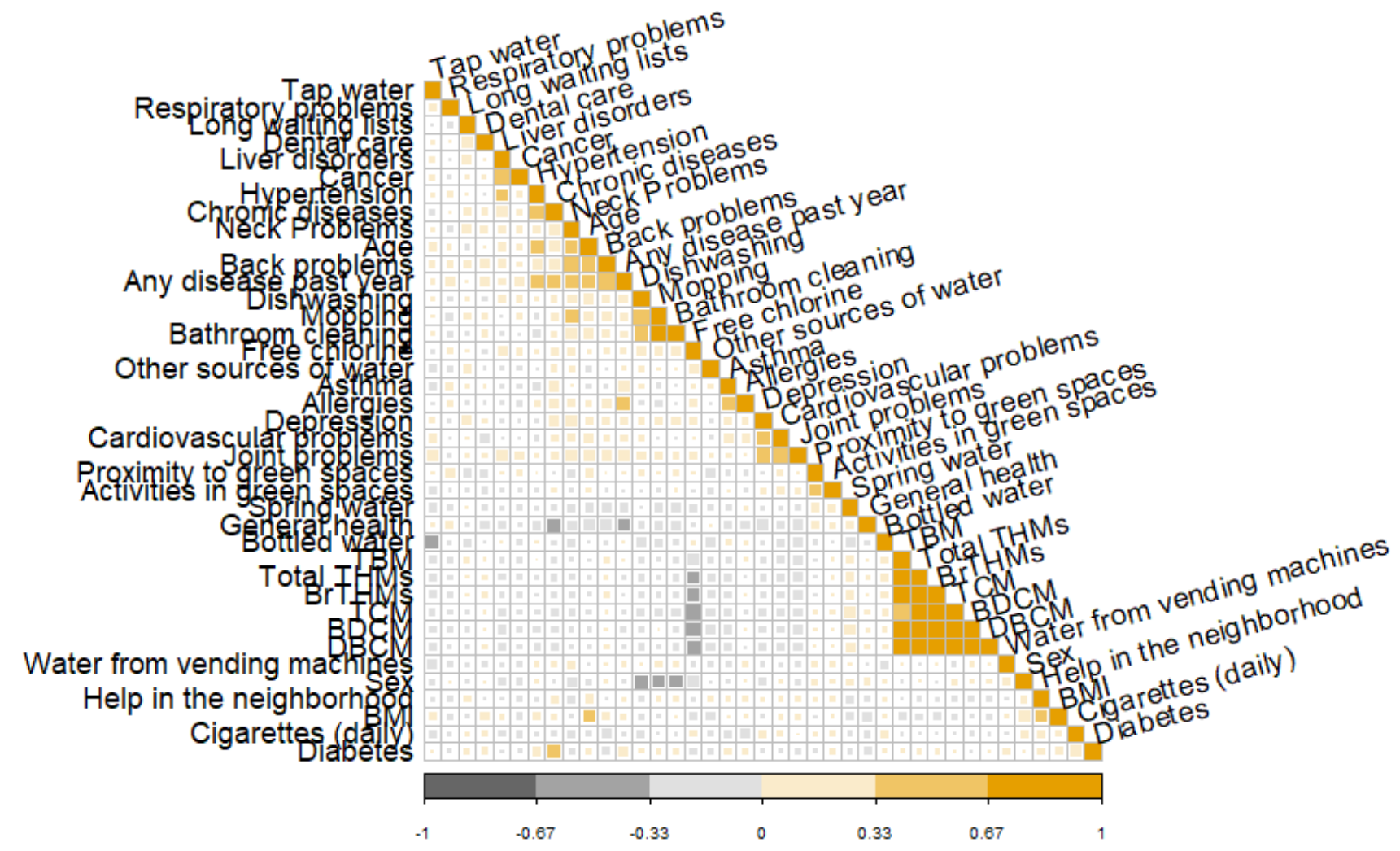


Figure 8

Circular plots of the correlations between the variables used in the environmental-wide analysis by block/group of variables. 


\section{A. General health circo plot}

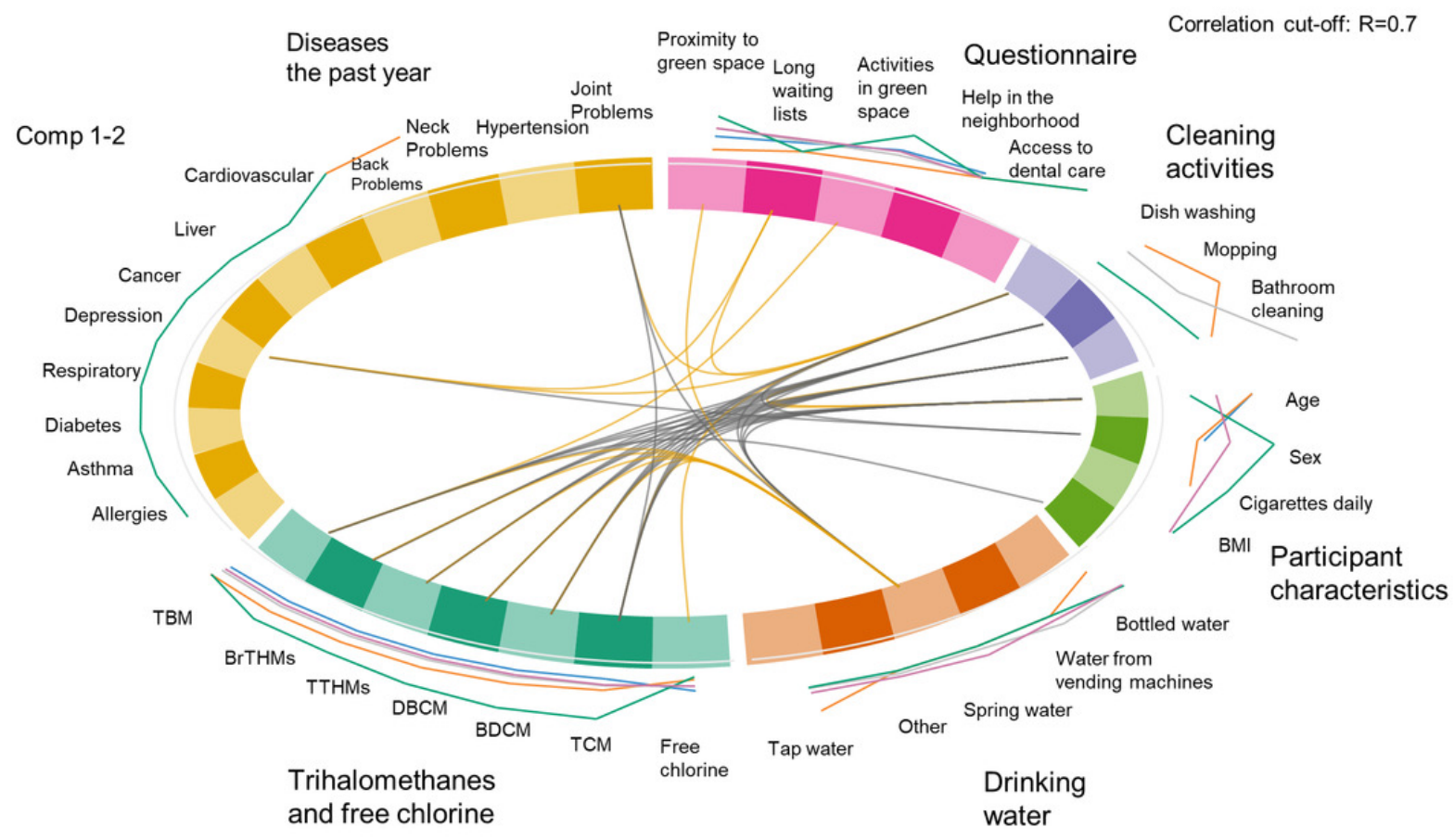

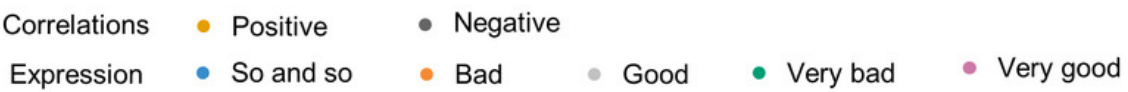

\section{B. Any disease the past year circo plot}

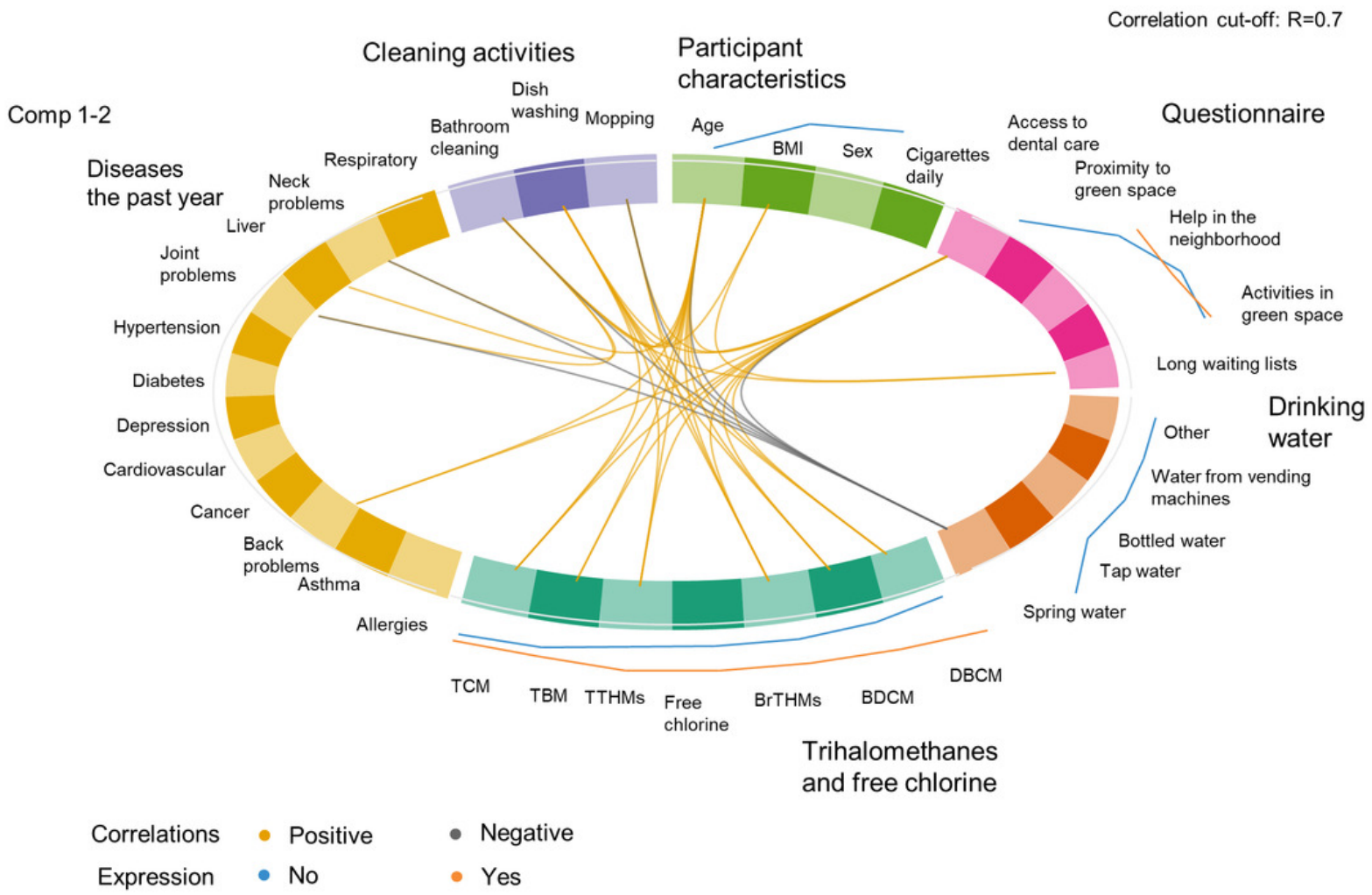




\section{Table $\mathbf{1}$ (on next page)}

Perceptions about environmental exposures among the respondents from the city of Limassol $(n=91)$. 
1

\begin{tabular}{lllll}
\hline & $\begin{array}{l}\text { Severely } \\
\text { exposed }\end{array}$ & $\begin{array}{l}\text { Somewhat } \\
\text { exposed }\end{array}$ & $\begin{array}{l}\text { Not } \\
\text { exposed }\end{array}$ & Don't know \\
\hline Noise (traffic, airplanes, factories, neighbours, & $38(42 \%)$ & $48(53 \%)$ & $5(5 \%)$ & $0(0 \%)$ \\
$\begin{array}{l}\text { animals, restaurants/bars/clubs) } \\
\text { Air pollution (fine dust, grime, fume, ozone) }\end{array}$ & $40(44 \%)$ & $40(44 \%)$ & $10(11 \%)$ & $1(1 \%)$ \\
$\begin{array}{l}\text { Bad smells (industry, agriculture, waste) } \\
\text { Water pollution (microbes/chemicals in drinking }\end{array}$ & $15(17 \%)$ & $35(38 \%)$ & $39(43 \%)$ & $2(2 \%)$ \\
water) & $8(9 \%)$ & $22(24 \%)$ & $31(34 \%)$ & $30(33 \%)$ \\
Soil contamination (eg., chemical waste dump) & $5(5 \%)$ & $15(17 \%)$ & $32(35 \%)$ & $39(43 \%)$ \\
\hline
\end{tabular}

2 
Table 2 (on next page)

Background participant for the urban population study conducted in Limassol, Cyprus. 
1

\begin{tabular}{cc}
\hline & Overall ( $\mathrm{n}=132)$ \\
\hline Age (mean (sd)) & $45.6(13.2)$ \\
Sex (\%) & \\
Females & $82(62.1)$ \\
Males & $50(37.9)$ \\
BMI (mean (sd)) & $26.25(5.06)$ \\
Marital Status (\%) & \\
Cohabitating & \\
Divorced & $8(6.1)$ \\
Married & $15(11.4)$ \\
Single & $82(62.1)$ \\
Widowed & $26(19.7)$ \\
Education (\%) & $1(0.8)$ \\
Primary school & \\
Gymnasium & $2(1.5)$ \\
High School/Technical School & $2(1.5)$ \\
Non-university tertiary education & $28(21.4)$ \\
Post-secondary education & $16(12.2)$ \\
Bachelor's degree (BSc/BA) & $6(4.6)$ \\
Master's degree or doctorate (MSc/MA, PhD) & $45(34.4)$ \\
\end{tabular}

2 


\section{Table 3 (on next page)}

Health status indicators assessed through the questionnaire among the 132 participants of the urban population study (Limassol, Cyprus). 
1

\begin{tabular}{lll}
\hline & & Overall $(\mathrm{n}=132)$ \\
\hline & & \\
General health assessment (\%) & Very good & $61(46.2)$ \\
& Good & $57(43.2)$ \\
& So and so & $12(9.1)$ \\
& Bad & $1(0.8)$ \\
& Very bad & $1(0.8)$ \\
& & \\
Chronic disease (\%) & Do not know & $5(3.8)$ \\
& I don't want to answer & $3(2.3)$ \\
& No & $97(73.5)$ \\
Any disease in the past year (\%) & Yes & $27(20.5)$ \\
& & \\
& No & $57(43.2)$ \\
& Yes & $75(56.8)$ \\
\hline
\end{tabular}

2

3 
Table 4 (on next page)

Chemical drinking water parameters analyzed in water samples collected in Limassol, Cyprus (2017) for $n=119$ samples collected from faucets without point of use filter and for $n=13$ samples collected from faucets with a point of use filter that could not be 


\begin{tabular}{|c|c|c|c|c|c|c|c|c|}
\hline \multicolumn{9}{|c|}{ Samples collected from faucets without filter } \\
\hline & $\mathrm{n}$ & Mean & $\begin{array}{l}\text { Standard } \\
\text { deviation }\end{array}$ & Median & 25th percentile & 75th percentile & Min & Max \\
\hline \multicolumn{9}{|c|}{ Regulated chemical parameters } \\
\hline Total THMs ( $\mu \mathrm{g} / \mathrm{L})$ & 119 & 30.5 & 32.22 & 15.2 & 6.99 & 50.83 & 3.17 & 210.54 \\
\hline \multicolumn{9}{|c|}{ Non-regulated chemical parameters } \\
\hline Free chlorine (mg/L) & 119 & 0.2 & 0.16 & 0.2 & 0.05 & 0.32 & ND & 0.65 \\
\hline $\mathrm{TCM}(\mu \mathrm{g} / \mathrm{L})$ & 119 & 2.1 & 2.24 & 1 & 0.47 & 3.16 & 0.07 & 13.25 \\
\hline $\mathrm{BDCM}(\mu \mathrm{g} / \mathrm{L})$ & 119 & 4.9 & 5.45 & 2 & 0.95 & 7.32 & 0.91 & 30.85 \\
\hline $\mathrm{DBCM}(\mu \mathrm{g} / \mathrm{L})$ & 119 & 9.1 & 11.18 & 2.4 & 1.18 & 15.52 & 1.07 & 66.19 \\
\hline $\mathrm{TBM}(\mu \mathrm{g} / \mathrm{L})$ & 119 & 14.4 & 14.63 & 7.7 & 3.94 & 22.6 & 0.06 & 100.26 \\
\hline BrTHMs $(\mu \mathrm{g} / L)$ & 119 & 28.4 & 30.24 & 13.5 & 6.22 & 46.94 & 3.10 & 197.29 \\
\hline \multicolumn{9}{|c|}{ Samples collected from faucets with filter } \\
\hline & $\mathrm{n}$ & Mean & $\begin{array}{l}\text { Standard } \\
\text { deviation }\end{array}$ & Median & 25th percentile & 75th percentile & Min & Max \\
\hline \multicolumn{9}{|c|}{ Regulated chemical parameters } \\
\hline Total THMs ( $\mu \mathrm{g} / \mathrm{L})$ & 13 & 9.6 & 9.0 & 5.0 & 4.0 & 9.9 & 3.2 & 28.4 \\
\hline \multicolumn{9}{|c|}{ Non-regulated chemical parameters } \\
\hline Free chlorine $(\mathrm{mg} / \mathrm{L})$ & 13 & 0.1 & 0.1 & 0.1 & 0.0 & 0.1 & ND & 0.3 \\
\hline $\mathrm{TCM}(\mu \mathrm{g} / \mathrm{L})$ & 13 & 0.9 & 1.0 & 0.5 & 0.5 & 0.7 & 0.2 & 3.8 \\
\hline $\mathrm{BDCM}(\mu \mathrm{g} / \mathrm{L})$ & 13 & 1.7 & 1.7 & 1.0 & 0.9 & 1.1 & 0.9 & 5.8 \\
\hline $\mathrm{DBCM}(\mu \mathrm{g} / \mathrm{L})$ & 13 & 2.1 & 2.4 & 1.2 & 1.1 & 1.5 & 1.0 & 9.5 \\
\hline TBM $(\mu \mathrm{g} / \mathrm{L})$ & 13 & 4.9 & 6.7 & 2.2 & 1.2 & 5.2 & 1.0 & 25.4 \\
\hline BrTHMs $(\mu \mathrm{g} / \mathrm{L})$ & 13 & 8.7 & 8.5 & 4.7 & 3.5 & 9.4 & 2.9 & 28.0 \\
\hline
\end{tabular}

2 


\section{Table 5 (on next page)}

Microbial drinking water parameters analyzed in water samples collected in Limassol, Cyprus (2017) for $n=119$ samples collected from faucets without point of use filter and for $n=13$ samples collected from faucets with a point of use filter that could not $b$ 
1

Samples collected from faucets without filter

$\mathrm{n}$

Regulated microbial parameters

E. coli (cfu per $100 \mathrm{~mL}$ )

Enterococcus spp. (cfu per $100 \mathrm{~mL}$ )

Non-regulated microbial parameters

Coliforms (per 100mL)

Pseudomonas aeruginosa (per $100 \mathrm{~mL}$ )

TVC at 22C (per 1mL)

TVC at 37C (per 1mL)

Regulated microbial parameters

E. coli (cfu per $100 \mathrm{~mL}$ )

Enterococcus spp. (cfu per $100 \mathrm{~mL}$ )

Non-regulated microbial parameters

Coliforms (per $100 \mathrm{~mL}$ )

Pseudomonas aeruginosa (per $100 \mathrm{~mL}$ )

TVC at 22C (per 1mL)

TVC at 37C (per 1mL)

n
Samples with at least $1 \mathrm{CFU}$

n (\%)

119

119

$0(0)$

$1(0.8)$

119

119

86

86

$22(22.7)$

$5(4.2)$

$12(14)$

30 (34.9)

Samples collected from faucets with filter Samples with at least $1 \mathrm{CFU}$

$\mathrm{n}(\%)$

$13 \quad 0(0)$

$13 \quad 0(0)$

$\begin{array}{ll}13 & 1(7.7) \\ 13 & 0(0) \\ 7 & 1(14.3) \\ 7 & 3(42.9)\end{array}$

2 


\section{Table 6(on next page)}

Self-reported choices of water sources by the study participants $(n=132)$ of the urban population study in Limassol, Cyprus. 
1

\begin{tabular}{|c|c|c|c|c|}
\hline \multicolumn{3}{|l|}{ Water sources } & \multicolumn{2}{|l|}{$\mathrm{n}(\%)$} \\
\hline \multicolumn{3}{|l|}{ Bottled water } & \multicolumn{2}{|l|}{40 (30.5) } \\
\hline \multicolumn{3}{|l|}{ Tap water } & \multicolumn{2}{|l|}{$29(22.1)$} \\
\hline \multicolumn{3}{|l|}{ Water from vending machines } & \multicolumn{2}{|l|}{$4(3.1)$} \\
\hline \multicolumn{3}{|l|}{ Spring water } & \multicolumn{2}{|l|}{$3(2.3)$} \\
\hline \multicolumn{3}{|l|}{ Tap water and bottled water } & \multicolumn{2}{|l|}{$37(28.2)$} \\
\hline \multicolumn{3}{|l|}{ Bottled water and spring water } & \multicolumn{2}{|l|}{$3(2.3)$} \\
\hline \multicolumn{3}{|l|}{ Bottled water and water from vending machines } & \multicolumn{2}{|l|}{$2(1.5)$} \\
\hline \multicolumn{3}{|l|}{ Tap water and other } & \multicolumn{2}{|l|}{$2(1.5)$} \\
\hline \multicolumn{3}{|l|}{ Tap water and water from vending machines } & \multicolumn{2}{|l|}{$2(1.5)$} \\
\hline \multicolumn{3}{|l|}{ Tap water and spring water } & \multicolumn{2}{|l|}{$1(0.8)$} \\
\hline \multicolumn{3}{|c|}{$\begin{array}{l}\text { Any three sources (tap water, bottled, water from vending machines, spring } \\
\text { water or other) }\end{array}$} & \multicolumn{2}{|l|}{$5(3.8)$} \\
\hline Number of glasses (about $250 \mathrm{~mL}$ ) per day by source & $\mathrm{n}$ & Mean & SD & Median \\
\hline Tap water & 130 & 2.52 & 3.6 & 0 \\
\hline Bottled water & 130 & 3.83 & 4.2 & 2.2 \\
\hline Water from vending machines & 130 & 0.54 & 2 & 0 \\
\hline Spring water & 130 & 0.33 & 1.3 & 0 \\
\hline Other source & 130 & 0.51 & 2.9 & 0 \\
\hline
\end{tabular}

2 